Article

\title{
Synthesis and Biological Evaluation of Novel Dehydroabietic Acid Derivatives Conjugated with Acyl-Thiourea Peptide Moiety as Antitumor Agents
}

\author{
Le Jin ${ }^{1, \dagger}$, Hong-En Qu ${ }^{1, \dagger}$, Xiao-Chao Huang ${ }^{1}$, Ying-Ming Pan ${ }^{1}$, Dong Liang ${ }^{1}$, \\ Zhen-Feng Chen ${ }^{1}$, Heng-Shan Wang ${ }^{1, *}$ and Ye Zhang ${ }^{1,2, *}$
}

1 State Key Laboratory Cultivation Base for the Chemistry and Molecular Engineering of Medicinal Resources, School of Chemistry \& Pharmaceutical Science of Guangxi Normal University, Yucai Road 15, Guilin 541004, China; E-Mails: jindonhua@163.com (L.J.); quhongen-2003@163.com (H.-E.Q.); viphuangxc@126.com (X.-C.H.); panym2005@sina.com (Y.-M.P.); sky_8912@163.com (D.L.); chenzfgxnu@yahoo.com (Z.-F.C.)

2 Department of Chemistry \& Pharmaceutical Science, Guilin Normal College, Xinyi Road 21, Guilin 541001, China

$\dagger$ These authors contributed equally to this work.

* Authors to whom correspondence should be addressed;

E-Mails: whengshan@163.com (H.-S.W.); zhangye81@126.com (Y.Z.);

Tel.: +86-773-2120-958 (H.-S.W. \& Y.Z.).

Academic Editor: William Chi-shing Cho

Received: 28 May 2015 / Accepted: 18 June 2015 / Published: 26 June 2015

\begin{abstract}
A series of dehydroabietic acid (DHAA) acyl-thiourea derivatives were designed and synthesized as potent antitumor agents. The in vitro pharmacological screening results revealed that the target compounds exhibited potent cytotoxicity against HeLa, SK-OV-3 and MGC-803 tumor cell lines, while they showed lower cytotoxicity against HL-7702 normal human river cells. Compound 9n $\left(\mathrm{IC}_{50}=6.58 \pm 1.11 \mu \mathrm{M}\right)$ exhibited the best antitumor activity against the HeLa cell line and even displayed more potent inhibitory activity than commercial antitumor drug 5-FU $\left(\mathrm{IC}_{50}=36.58 \pm 1.55 \mu \mathrm{M}\right)$. The mechanism of representative compound $\mathbf{9 n}$ was then studied by acridine orange/ethidium bromide staining, Hoechst 33,258 staining, JC-1 mitochondrial membrane potential staining, TUNEL assay and flow cytometry, which illustrated that this compound could induce apoptosis in HeLa cells. Cell cycle analysis indicated that compound 9n mainly arrested HeLa cells in
\end{abstract}


the S phase stage. Further investigation demonstrated that compound 9n induced apoptosis of HeLa cells through a mitochondrial pathway.

Keywords: dehydroabietic acid; chiral amino acid; thioureas; antitumor activity; apoptosis

\section{Introduction}

As one of the main causes of mortality worldwide, cancer has became a global health problem. Thus, the design and synthesis of new antitumor drugs has attracted considerable efforts. Over the past decades, researchers have long explored natural products in the quest for new antitumor drugs. The success of doxorubicin, paclitaxel, and vinblastine has revealed that natural compounds are a rich source of antitumor drugs [1-3]. In fact, about $60 \%$ of antitumor agents derive from natural compounds [4].

As a natural occurring diterpene, rosin acid, DHAA and its derivatives display a fascinating spectrum of biological activities, such as anti-ulcer, antimicrobial, anxiolytic, antiviral and antitumor activities [5-9]. Recent reports have indicated that DHAA and their analogs have anticancer activity in many human cancer cells, including cervical carcinoma cells, hepatocellular carcinoma cells and breast cancer cells [10]. Our previous study has also demonstrated that the $\alpha$-aminophosphonate, dipeptide, thiourea derivatives of DHAA showed potent antitumor activity [11-13]. So many DHAA derivatives containing functional groups have been designed and synthesized to screen for new potential antitumor agents [14-16].

Continuing our research program on the synthesis of DHAA derivatives as potent antitumor agents, the present work in this paper is to design and synthesize a series of new DHAA acyl-thiourea derivatives by the introduction of acyl-thiourea group in the carboxylic acid group of DHAA (Scheme 1). Many acyl-thiourea derivatives exhibit good inhibitory activity against malignant tumors [17], and our previous work has also demonstrated that the introductions of $\alpha$-aminophosphonate, dipeptide, and thiourea on DHAA could lead to improved antitumor activity. Thus, it is reasonable to consider that well-designed functional groups would enable a fine-tuning of special properties of a pharmacy core, and to expect that the introduction of an acyl-thiourea moiety on a DHAA skeleton may lead to good antitumor activity. Therefore, the synthetic route to DHAA acyl-thiourea derivatives was herein designed and carried out. Also, the cytotoxicity in vitro against the HeLa, SK-OV-3 and MGC-803 tumor cell lines and HL-7702 normal human river cell line was evaluated. Furthermore, the molecules mechanism of apoptotic pathway induced apoptosis in HeLa cells by the representative compound of the target compound was also investigated. 

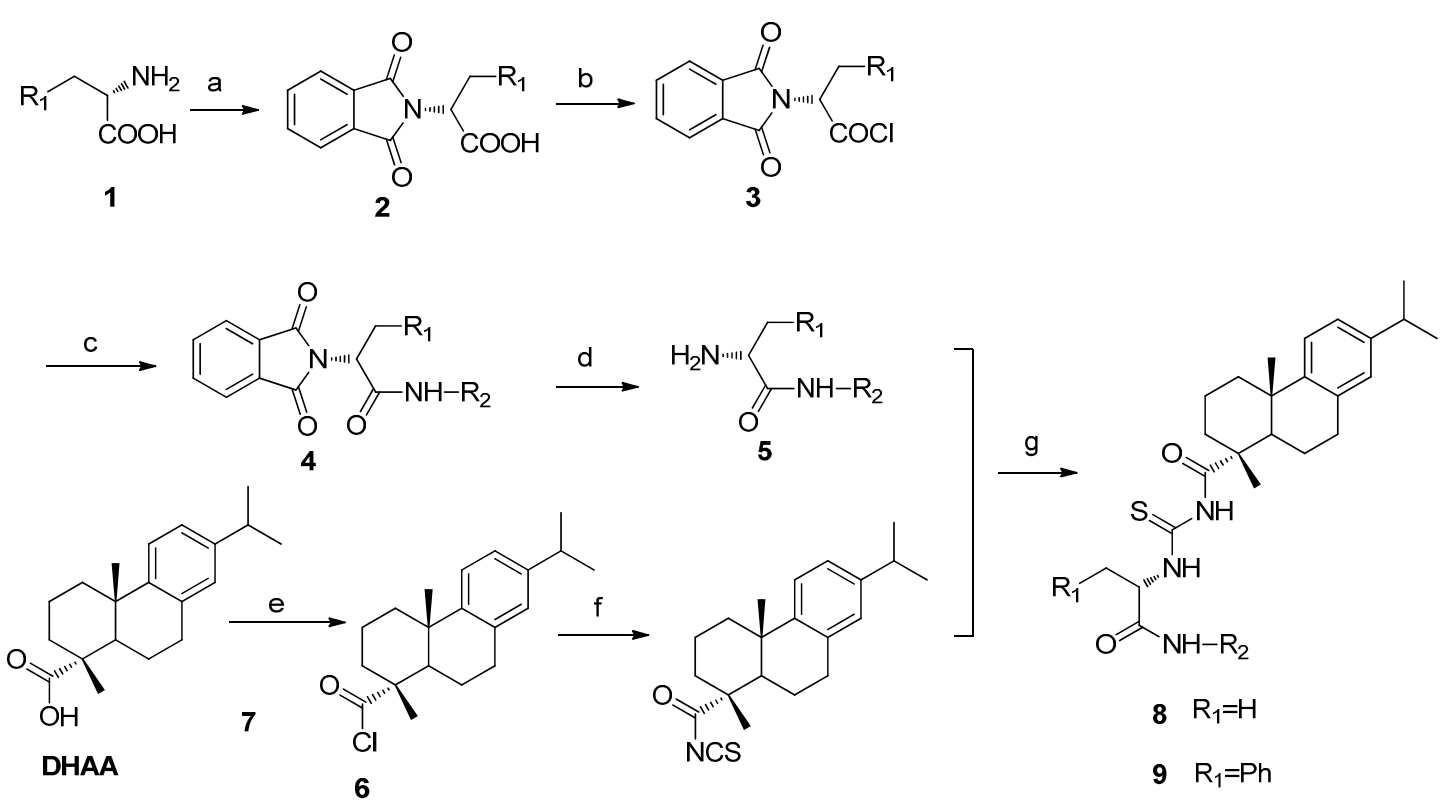

Scheme 1. Synthetic pathway to target compounds 8a-8o and 9a-9o. Reagents and conditions: (a) phthalic anhydride, $\mathrm{CH}_{3} \mathrm{COOH}, 50{ }^{\circ} \mathrm{C}$; (b) oxalyl chloride, $\mathrm{CH}_{2} \mathrm{Cl}_{2}$, r.t.; (c) aromatic primary amines, $\mathrm{Et}_{3} \mathrm{~N}, \mathrm{CH}_{2} \mathrm{Cl}_{2}$, r.t.; (d) hydrazine hydrate, $\mathrm{CH}_{3} \mathrm{OH}$, r.t.; (e) oxalyl chloride, $\mathrm{CH}_{2} \mathrm{Cl}_{2}$, r.t.; (f) $\mathrm{C}_{6} \mathrm{H}_{5} \mathrm{CH}_{3}, \mathrm{KSCN} 110{ }^{\circ} \mathrm{C}$; (g) $\mathrm{CH}_{2} \mathrm{Cl}_{2}$, r.t.

\section{Results and Discussion}

\subsection{Chemistry}

DHAA acyl-thiourea derivatives were synthesized as outlined in Scheme 1. Compound 2 was prepared by the condensation of L-amino acid 1 with phthalic anhydride in the presence of acetic acid. Compound $\mathbf{3}$ was obtained by the treatment of compound $\mathbf{2}$ and oxalyl chloride, and it was then treated with series of aromatic primary amines to offer compounds $\mathbf{4}$. Compounds 5 were synthesized by the treatment of compounds 4 with hydrazine hydrate in the presence of ethanol at room temperature. Meanwhile DHAA was treated with oxalyl chloride to offer compound $\mathbf{6}$. Then compound $\mathbf{6}$ was treated with $\mathrm{KSCN}$ to offer compound 7. Compounds 8 and $\mathbf{9}$ were finally acquired by the condensation of compound 7 and compounds 5 in $\mathrm{CH}_{2} \mathrm{Cl}_{2}$ at room temperature. The structures of DHAA acyl-thiourea derivatives 8-9 were confirmed by ${ }^{1} \mathrm{H}$ NMR, ${ }^{13} \mathrm{C}$ NMR and high-resolution mass spectroscopy.

\subsection{Biological Activity}

\subsubsection{MTT Assay}

The in vitro cytotoxic potency of DHAA acyl-thiourea derivatives $8 \mathbf{a}-\mathbf{8 0}$ and $9 \mathbf{a}-\mathbf{9 0}$ were evaluated by 3-(4,5-dimethylthiazol-2-yl)-2,5-diphenyltetrazolium bromide (MTT) assay against HeLa, SK-OV-3 and MGC-803 tumor cell lines, with 5-FU as the positive control. The tested results were shown in Table 1. 
Table 1. Effect of compounds $8 \mathbf{a}-\mathbf{8 0}$ and $\mathbf{9 a}-\mathbf{9 0}$ against cell viability of different cell lines.

\begin{tabular}{|c|c|c|c|c|c|c|}
\hline \multirow[t]{2}{*}{ Compound } & \multicolumn{6}{|c|}{$\mathrm{IC}_{50}\left(\boldsymbol{\mu M} \cdot \mathbf{L}^{-1}\right)$} \\
\hline & $\mathbf{R}_{1}$ & $\mathbf{R}_{2}$ & HeLa & SK-OV-3 & MGC-803 & HL-7702 \\
\hline $8 a$ & $\mathrm{H}$ & $\mathrm{Ph}$ & $31.09 \pm 2.13$ & $26.49 \pm 2.53$ & $28.49 \pm 1.79$ & $47.59 \pm 2.43$ \\
\hline $8 b$ & $\mathrm{H}$ & $o-\mathrm{Ph}-\mathrm{CH}_{3}$ & $29.19 \pm 2.43$ & $42.81 \pm 1.42$ & $19.17 \pm 1.66$ & $52.51 \pm 1.25$ \\
\hline $8 c$ & $\mathrm{H}$ & $p-\mathrm{Ph}-\mathrm{CH}_{3}$ & $38.71 \pm 3.65$ & $50.87 \pm 4.11$ & $24.85 \pm 1.64$ & $61.67 \pm 3.41$ \\
\hline $8 d$ & $\mathrm{H}$ & $o-\mathrm{Ph}-\mathrm{Cl}$ & $19.73 \pm 1.23$ & $48.33 \pm 4.21$ & $20.55 \pm 1.57$ & $69.43 \pm 4.23$ \\
\hline $8 e$ & $\mathrm{H}$ & $p$-Ph-Cl & $36.15 \pm 3.31$ & $36.11 \pm 3.28$ & $21.73 \pm 1.69$ & $57.67 \pm 3.66$ \\
\hline $8 f$ & $\mathrm{H}$ & $o-\mathrm{Ph}-\mathrm{OCH}_{3}$ & $28.08 \pm 2.11$ & $23.03 \pm 3.01$ & $17.95 \pm 1.73$ & $44.73 \pm 3.34$ \\
\hline $8 g$ & $\mathrm{H}$ & $p-\mathrm{Ph}-\mathrm{OCH}_{3}$ & $27.42 \pm 2.43$ & $26.81 \pm 2.47$ & $18.56 \pm 1.72$ & $43.61 \pm 2.43$ \\
\hline $8 h$ & $\mathrm{H}$ & $o-\mathrm{Ph}-\mathrm{F}$ & $23.27 \pm 1.55$ & $31.81 \pm 2.36$ & $26.06 \pm 2.37$ & $53.52 \pm 2.35$ \\
\hline $8 \mathbf{i}$ & $\mathrm{H}$ & $p-\mathrm{Ph}-\mathrm{F}$ & $30.24 \pm 2.55$ & $32.48 \pm 2.64$ & $29.42 \pm 2.77$ & $54.45 \pm 2.34$ \\
\hline $8 \mathbf{j}$ & $\mathrm{H}$ & $o-\mathrm{Ph}-\mathrm{Br}$ & $22.75 \pm 1.55$ & $39.08 \pm 3.56$ & $27.93 \pm 3.26$ & $59.57 \pm 3.54$ \\
\hline $8 \mathbf{k}$ & $\mathrm{H}$ & $p$-Ph-Br & $19.03 \pm 1.46$ & $40.77 \pm 3.57$ & $29.98 \pm 1.24$ & $54.65 \pm 3.65$ \\
\hline 81 & $\mathrm{H}$ & 3,5-di-methyl-Ph & $18.64 \pm 1.24$ & $32.97 \pm 2.59$ & $13.88 \pm 1.32$ & $55.29 \pm 2.65$ \\
\hline $8 m$ & $\mathrm{H}$ & 1-Naphthyl & $46.55 \pm 4.77$ & $49.42 \pm 4.64$ & $36.48 \pm 3.24$ & $59.45 \pm 4.65$ \\
\hline $8 n$ & $\mathrm{H}$ & 2-pyridyl & $14.32 \pm 1.33$ & $25.23 \pm 2.43$ & $19.33 \pm 1.32$ & $48.75 \pm 2.44$ \\
\hline 80 & $\mathrm{H}$ & 3,4,5-tri-methoxyl-Ph & $18.06 \pm 1.23$ & $29.56 \pm 2.67$ & $22.67 \pm 1.77$ & $49.22 \pm 2.65$ \\
\hline 9a & $\mathrm{Ph}$ & $\mathrm{Ph}$ & $25.68 \pm 2.23$ & $17.01 \pm 1.13$ & $26.64 \pm 3.25$ & $37.45 \pm 1.44$ \\
\hline $9 b$ & $\mathrm{Ph}$ & $o-\mathrm{Ph}-\mathrm{CH}_{3}$ & $17.66 \pm 1.34$ & $18.49 \pm 1.44$ & $14.14 \pm 1.12$ & $38.56 \pm 1.65$ \\
\hline $9 c$ & $\mathrm{Ph}$ & $p-\mathrm{Ph}-\mathrm{CH}_{3}$ & $19.08 \pm 1.08$ & $16.21 \pm 1.98$ & $19.18 \pm 1.66$ & $36.24 \pm 1.39$ \\
\hline 9d & $\mathrm{Ph}$ & $o-\mathrm{Ph}-\mathrm{Cl}$ & $16.99 \pm 1.76$ & $16.93 \pm 1.43$ & $20.35 \pm 3.41$ & $36.53 \pm 1.43$ \\
\hline $9 e$ & $\mathrm{Ph}$ & $p-\mathrm{Ph}-\mathrm{Cl}$ & $17.21 \pm 1.25$ & $18.47 \pm 1.27$ & $17.08 \pm 2.87$ & $38.49 \pm 1.22$ \\
\hline $9 f$ & $\mathrm{Ph}$ & $o-\mathrm{Ph}-\mathrm{OCH}_{3}$ & $28.06 \pm 2.23$ & $18.91 \pm 1.72$ & $20.66 \pm 1.41$ & $38.44 \pm 1.45$ \\
\hline $9 g$ & $\mathrm{Ph}$ & $p$-Ph-OCH 3 & $15.58 \pm 1.53$ & $20.10 \pm 1.78$ & $26.13 \pm 2.63$ & $41.15 \pm 1.32$ \\
\hline $9 h$ & $\mathrm{Ph}$ & $o-\mathrm{Ph}-\mathrm{F}$ & $18.83 \pm 1.45$ & $28.79 \pm 2.32$ & $24.67 \pm 3.33$ & $49.39 \pm 2.64$ \\
\hline $9 \mathbf{i}$ & $\mathrm{Ph}$ & $p$-Ph-F & $23.71 \pm 1.01$ & $26.47 \pm 2.07$ & $21.40 \pm 1.88$ & $46.44 \pm 2.44$ \\
\hline $\mathbf{9 j}$ & $\mathrm{Ph}$ & $o-\mathrm{Ph}-\mathrm{Br}$ & $12.66 \pm 1.03$ & $40.27 \pm 3.41$ & $21.33 \pm 1.27$ & $60.47 \pm 3.43$ \\
\hline $9 k$ & $\mathrm{Ph}$ & $p-\mathrm{Ph}-\mathrm{Br}$ & $15.66 \pm 1.13$ & $46.69 \pm 4.76$ & $25.51 \pm 2.47$ & $66.49 \pm 4.48$ \\
\hline 91 & $\mathrm{Ph}$ & 3,5-di-methyl-Ph & $15.81 \pm 1.55$ & $31.52 \pm 2.23$ & $18.05 \pm 152$ & $53.42 \pm 2.24$ \\
\hline $9 m$ & $\mathrm{Ph}$ & 1-Naphthyl & $12.75 \pm 1.20$ & $15.29 \pm 1.73$ & $22.87 \pm 1.66$ & $35.59 \pm 1.53$ \\
\hline $9 n$ & $\mathrm{Ph}$ & 2-pyridyl & $6.58 \pm 1.11$ & $19.61 \pm 1.87$ & $16.90 \pm 1.56$ & $39.61 \pm 1.47$ \\
\hline 90 & $\mathrm{Ph}$ & 3,4,5-tri-methoxyl-Ph & $17.51 \pm 1.54$ & $29.30 \pm 2.04$ & $29.32 \pm 2.09$ & $59.34 \pm 2.54$ \\
\hline DHA & & & $30.35 \pm 3.45$ & $87.52 \pm 4.12$ & $>100$ & $\mathrm{NT}^{\mathrm{a}}$ \\
\hline 5-FU & & & $36.58 \pm 1.55$ & $30.25 \pm 1.13$ & $34.85 \pm 1.75$ & $\mathrm{NT}^{\mathrm{a}}$ \\
\hline
\end{tabular}

${ }^{\mathrm{a}} \mathrm{IC}_{50}$ values are presented as the mean $\pm \mathrm{SD}$ (standard error of the mean) from three independent experiments.

As can be seen from the Table 1, most target compounds showed certain anticancer activities against the tumor cells (HeLa, SK-OV-3, and MGC-803) as compared with the control 5-fluorouracil (5-FU). Compound 9n ( $\left.\mathrm{IC}_{50}=6.58 \pm 1.11 \mu \mathrm{M}\right)$ exhibited the best antitumor activity against the HeLa cell line and even displayed more potent inhibitory activity than commercial antitumor 5-FU $\left(\mathrm{IC}_{50}=36.58 \pm 1.55 \mu \mathrm{M}\right)$. All the compounds showed lower cytotoxicity on HL-7702 cells than on that of these three cancer cell lines.

From the above results, some interesting structure-activity relationships could be concluded: (1) the introduction of acyl-thiourea was significant for improving their activity; (2) in HeLa, SK-OV-3 and 
MGC-803 assays, the antitumor activities were found to be in the order of ortho- > para-; (3) compared the antitumor activity of compounds $\mathbf{8}$ with $\mathbf{9}$, it could be found that the antitumor activity of compounds 9 were better than that of $\mathbf{8}$. It was important to note that the introduction of a benzene group at $\mathrm{R}_{1}$ was important for improving antitumor activities.

\subsubsection{Apoptosis Assessment by AO/EB Staining}

The cytotoxicity of compound $9 \mathrm{n}$ at a concentration of $10 \mu \mathrm{M}$ against HeLa cells from 12 to $24 \mathrm{~h}$ was detected by AO/EB staining, and Hela cells not treated with the 9n were used as control for $48 \mathrm{~h}$. The results are shown in Figure 1. Results depicted in Figure 1 indicate that control cells did not take up EB and appeared faint orange-red, while cells treated with $9 \mathrm{n}$ at $10 \mu \mathrm{M}$ showed obvious apoptotic characters (chromatin condensation or fragmentation) and appeared intense orange-red, as dead cells had ruptured membranes, which allowed EB to enter into the cells. Also due to the AO uptake, control cells appeared green while 9n treated cells appeared green to intense green as apoptotic cells had much more permeable membranes. These findings indicated that compound $\mathbf{9 n}$ was able to induce apoptosis.

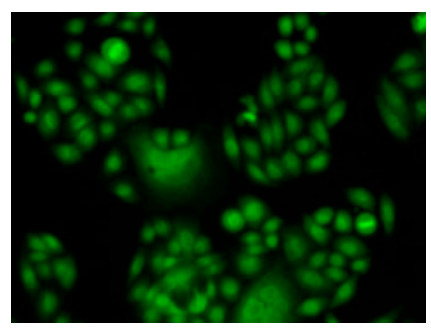

(a)



(b)

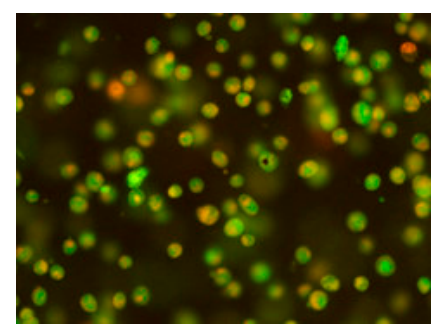

(c)

Figure 1. AO/EB staining of compound 9n in HeLa cells. (a) Not treated with the 9n were used as control at for $24 \mathrm{~h}$ and $(\mathbf{b}, \mathbf{c})$ treatment with compound $9 \mathbf{n}(10 \mu \mathrm{M})$ for 12 and $24 \mathrm{~h}$, respectively.

\subsubsection{Apoptosis Assessment by Hoechst 33258 Staining}

Hoechst 33258 which stains the cell nucleus, is a membrane permeable dye with blue fluorescence. Live cells with uniformly light blue nuclei were obviously detected under the fluorescence microscope after treatment with Hoechst 33258 whereas apoptotic cells had bright blue nuclei due to karyopyknosis and chromatin condensation. However, the nuclei of dead cells could not be stained. HeLa cells treated with compound 9n at $10 \mu \mathrm{M}$ from 12 to $24 \mathrm{~h}$ were stained with Hoechst 33258 . HeLa cells not treated with compound 9n were used as control for $24 \mathrm{~h}$. The results are shown in Figure 2. As shown in Figure 2, HeLa cells not treated with compound 9n were normally blue (in the web version). It is worth noting that, for $\mathbf{9 n}$ treatment, the cells displayed strong blue fluorescence and indicated typical apoptotic morphology after 12 and $24 \mathrm{~h}$. The observation revealed that compounds 9n induced apoptosis in HeLa cells. 


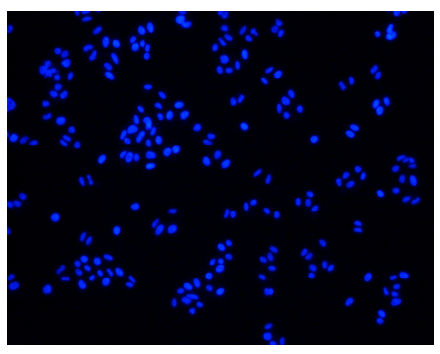

(a)



(b)

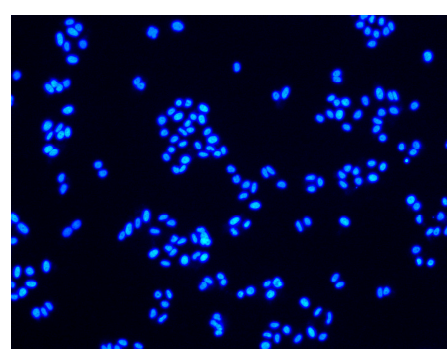

(c)

Figure 2. Hoechst 33,258 staining of compound 9n in HeLa cells. (a) Cells not treated with compound 9n were used as control for $24 \mathrm{~h}$ and $(\mathbf{b}, \mathbf{c})$ treatment with compound 9n $(10 \mu \mathrm{M})$ for 12 and $24 \mathrm{~h}$, respectively.

\subsubsection{Mitochondrial Membrane Potential Staining}

Apoptosis plays an important role in cancer, since its induction in tumor cells is essential for successful treatment [18]. Mitochondria play key roles in apoptosis through the release of pro-apoptotic factors such as cytochrome $c$ and apoptosis-inducing factor [19,20]. In order to further investigate the apoptosis-inducing effect of target compound 9n, mitochondrial membrane potential changes were designed and detected, using the fluorescent probe JC-1. JC-1 exhibited potential dependent accumulation in mitochondria, indicated by a fluorescence emission shift from red ( $\sim 590 \mathrm{~nm})$ to green $(\sim 545 \mathrm{~nm})$ [21]. In the control cells, JC-1 could aggregate in mitochondria and present high red fluorescence. However, in cells undergoing apoptosis, where the mitochondrial potential has collapsed, JC-1 exists in the cytosol as a monomer that emits green fluorescence. HeLa cells treated with compound 9n at $10 \mu \mathrm{M}$ from 12 to $24 \mathrm{~h}$ were stained with JC-1 and cells not treated with the compound 9n were used as control for $24 \mathrm{~h}$. The results are shown in Figure 3. The JC-1 monomer and J-aggregates were excited at 514 and $585 \mathrm{~nm}$, respectively, and light emissions were collected at 515-545 nm (green) and 570-600 nm (red). For fluorescence microscopy, Figure 3 showed that cells not treated with the compound 9n were normally red (in the web version), while for compound 9n treatment, cells showed strong green fluorescence and indicated typical apoptotic morphology after 12 and $24 \mathrm{~h}$. Therefore, it could be concluded that compound 9n induced apoptosis against HeLa cell line. The results were identical with that of previous experiment of Hoechst 33,258 staining.

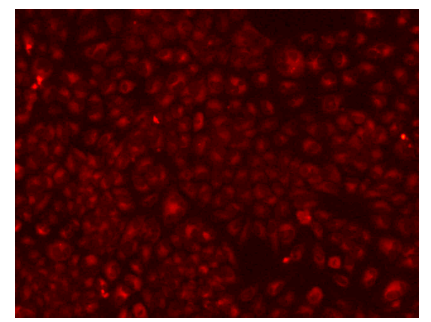

(a)

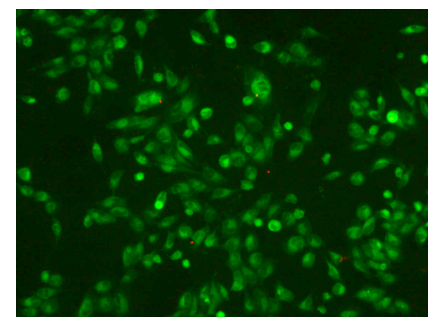

(b)

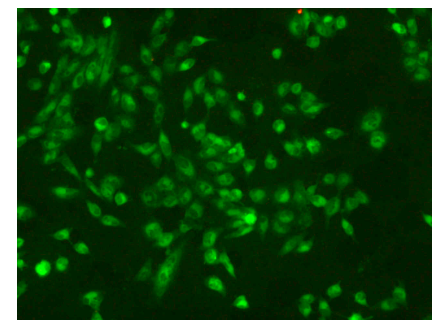

(c)

Figure 3. JC-1 mitochondrial membrane potential staining of compound $9 \mathbf{n}$ in HeLa cells. (a) Cells not treated with the $9 \mathrm{n}$ were used as control at for $24 \mathrm{~h}$ and $(\mathbf{b}, \mathbf{c})$ treatment with compound 9n $(10 \mu \mathrm{M})$ for 12 and $24 \mathrm{~h}$, respectively. 


\subsubsection{TUNEL Assay}

To further define the mechanism of cell death caused by compound 9n, HeLa cells were treated with compound 9n at $10 \mu \mathrm{M}$ from 12 to $24 \mathrm{~h}$ and the DNA fragmentation was measured by the TUNEL assay. TUNEL (terminal-deoxynucleotidyl transferase meditated nick end labeling) is a common method for identifying apoptotic cells in situ by detecting DNA fragmentation. When the genomic DNA is broken, the exposed 3'-OH at the end of deoxynucleotide transfer as the catalytic plus green fluorescent probes fluorescein (FITC) labeled dUTP, which can be detected by fluorescence microscopy or flow cytometry, as indicated by a green color (in the web version). The results are illustrated in Figure 4. For fluorescence microscopy, Figure 4 shows that HeLa cells treated with the compound 9n at different time appeared in green (in the web version), exhibiting that compound 9n significantly induced apoptosis against the HeLa cell line. The results were in good agreement with the previous experiments.

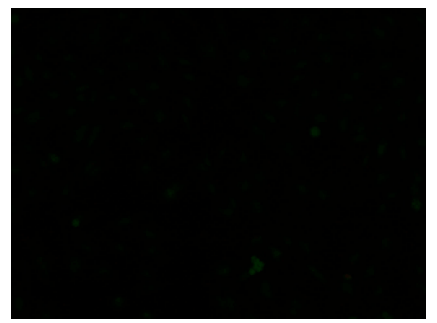

(a)

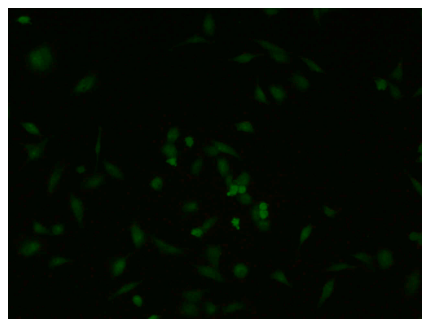

(b)

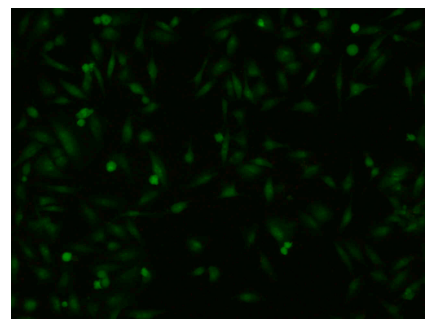

(c)

Figure 4. TUNEL assay of compound $9 \mathbf{n}$ in HeLa cells. (a) Cells not treated with the 9n were used as control for $24 \mathrm{~h}$ and $(\mathbf{b}, \mathbf{c})$ treatment with compound $9 \mathrm{n}(10 \mu \mathrm{M})$ for 12 and $24 \mathrm{~h}$, respectively.

\subsubsection{Apoptosis Study by Flow Cytometry Assay}

Annexin V/PI staining was performed to distinguish apoptotic and necrotic cell deaths. The apoptosis ratios induced by compound $9 \mathbf{n}$ in HeLa cells were quantitatively determined by flow cytometry (Figure 5). Four quadrant images were observed by flow cytometric analysis: the Q1 area represented damaged cells appearing in the process of cell collection, the Q2 region showed necrotic cells and later period apoptotic cells; the early apoptotic cells were located in the Q3 area and the Q4 area showed normal cells. Figure 5 revealed that compound 9n could induce apoptosis in HeLa cells. Apoptosis ratios (including the early and late apoptosis ratios) for compound 9n were obtained after $12 \mathrm{~h}$ of treatment at the concentration of 10 and $15 \mu \mathrm{M}$. The apoptosis of HeLa cells treated with target compound 9n increased gradually in a concentration manner. The apoptosis ratios of compound 9n measured at different concentration points were found to be $21.11 \%$ and $42.75 \%$, respectively, while that of the control was $1.521 \%$. The results illustrated that target compound 9n suppressed cell proliferation by inducing apoptosis. 


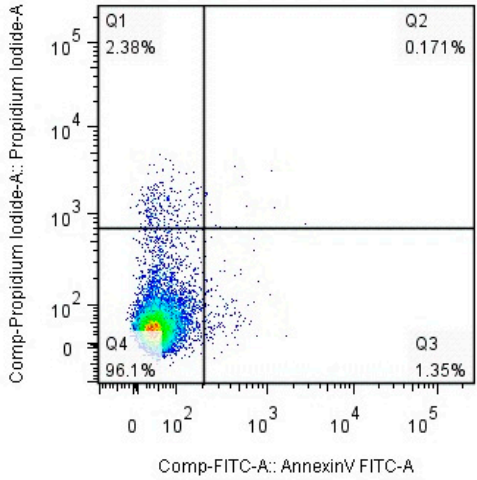

(a)

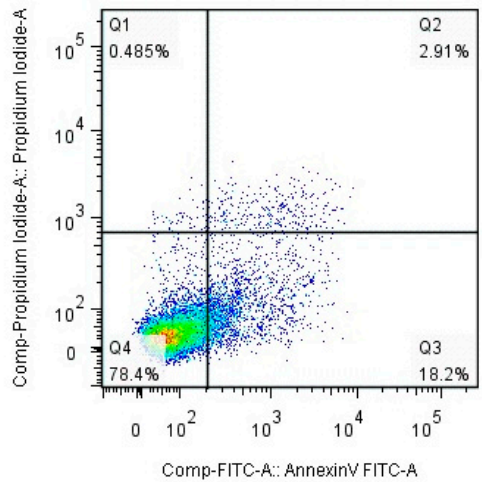

(b)

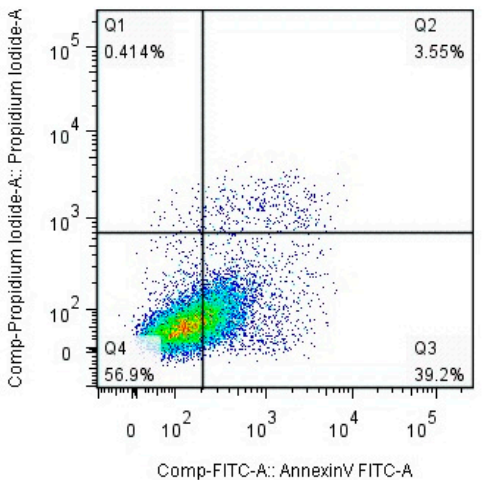

(c)

Figure 5. Apoptosis ratio detection of compound 9n by Annexin V/PI assay. (a) Cells not treated with compund 9n were used as control for $12 \mathrm{~h}$; (b,c) HeLa cells were treated with compound $9 \mathrm{n}$ at 10 and $15 \mu \mathrm{M}$ for $12 \mathrm{~h}$, respectively.

\subsubsection{Investigation of Cell Cycle Distribution}

Many anticancer drugs interact with cells leading to cell growth arrest. To determine the possible role of cell cycle arrest in DHAA derivative induced growth inhibition, HeLa cells were treated with different concentrations of compound $\mathbf{9 n}$. Cell cycle distribution was investigated by flow cytometric analysis after staining of the DNA with propidium iodide (PI). After treatment with compound 9n at different concentrations for $48 \mathrm{~h}$, it was observed that the cells accumulated in G1 and G2 phase were gradually decreased, while $\mathrm{S}$ period cells compared with the control cells were gradually increased (Figure 6). These results suggested that target compound 9n mainly arrested HeLa cells in the S stage.



(a)

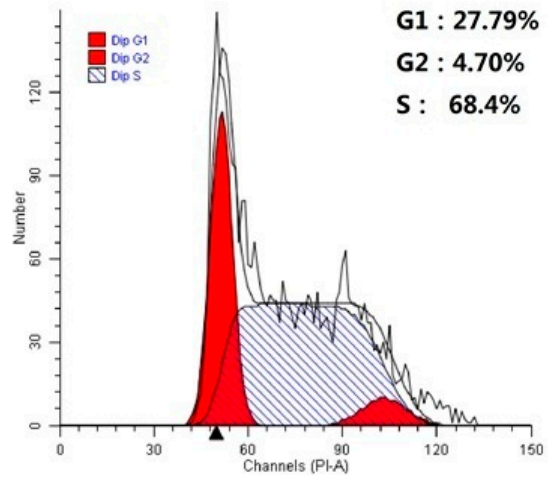

(b)

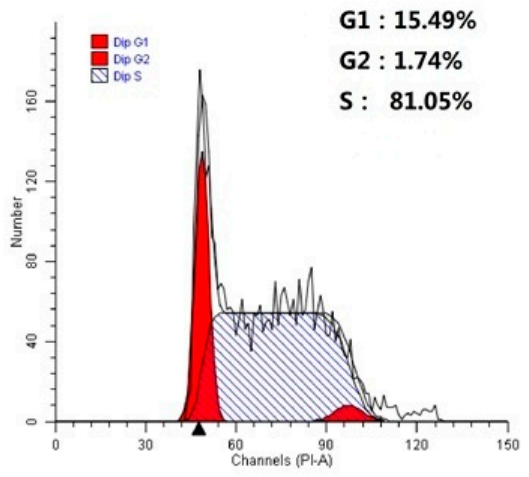

(c)

Figure 6. Investigation of cell cycle distribution by flow cytometric analysis. (a) Untreated HeLa cells as a control; $(\mathbf{b}, \mathbf{c})$ Cells treated with increasing concentrations of compound 9n $(10,15 \mu \mathrm{M})$ for $48 \mathrm{~h}$.

\subsubsection{ROS Generation Assay and Intracellular $\mathrm{Ca}^{2+}$ Release}

Recently, oxidative damage to the mitochondrial membrane due to increased generation of reactive oxygen species (ROS) has been shown to play an important role in apoptosis [22-24]. Mitochondria 
have also been implicated as a source of ROS during apoptosis. In addition, a decrease of mitochondria membrane potential has recently been shown to lead to increased generation of ROS and apoptosis [25]. We herein studied whether the loss of mitochondrial transmembrane potential resulting in the generation of ROS measured as described in our previous papers, using the fluorescent probe 2,7-dichlorofluorescein diacetate (DCF-DA) determined by fluorescence microscopy. HeLa cells treated with compound 9 n displayed stronger fluorescence intensity in cytoplasm, while HeLa cells not treated with compound 9n under the same experimental procedures were used as control and the fluorescence detected in these cells was weak and spread all over the cells. Fluorescence microscopy revealed that compound 9n induced an increase of the ROS level in HeLa cells, as seen in Figure 7, indicating that compound 9n significantly induced apoptosis in HeLa cells. Calcium has long been recognized as a significant participant in cell apoptosis. Therefore, we investigated whether compound 9n inducing cell death was involved in the production of $\mathrm{Ca}^{2+}$. To investigate the effect of compound 9n on calcium release, HeLa cells treated with compound 9n at $10 \mu \mathrm{M}$ for $24 \mathrm{~h}$ were loaded with the $\mathrm{Ca}^{2+}$ indicator Fluo-3-acetoxymethyl-ester (Fluo-3/AM, $5 \mu \mathrm{M}$; Beyotime, Jiangsu, China). Figure 8 shows that HeLa cells treated with compound 9n displayed stronger green fluorescence, while HeLa cells not treated with compound 9n under the same experimental procedures were used as control and the fluorescence detected in these cells were exhibited normally as green (in the web version). These results imply that the increment of ROS and intracellular $\mathrm{Ca}^{2+}$ released might play a role as an early mediator in compound 9n induced apoptosis.

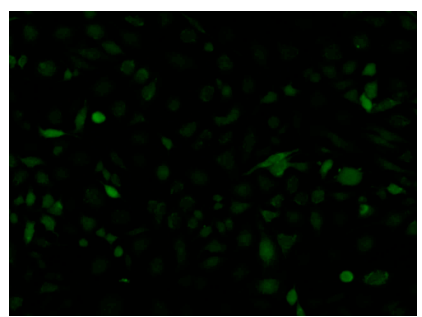

(a)

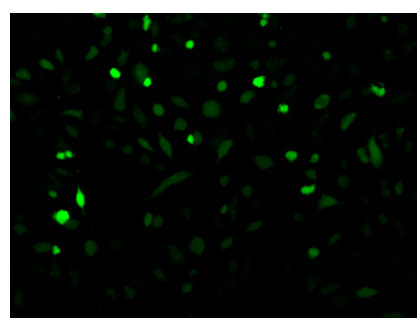

(b)

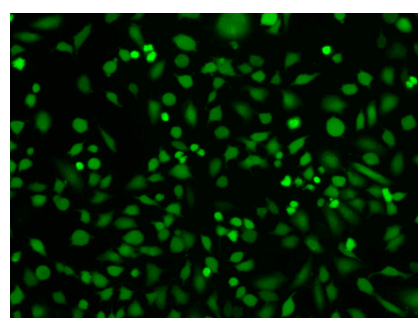

(c)

Figure 7. ROS generation assay of compound 9n in HeLa cells. (a) Cells not treated with compound 9n were used as control for $12 \mathrm{~h}$ and $(\mathbf{b}, \mathbf{c})$ treatment with compound 9n (10, $15 \mu \mathrm{M}$ ) for $12 \mathrm{~h}$, respectively.

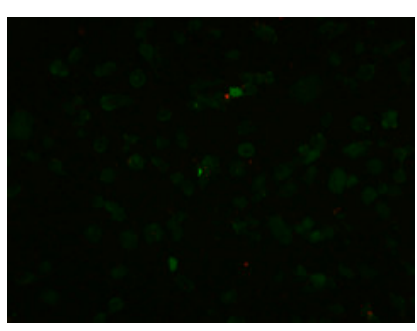

(a)

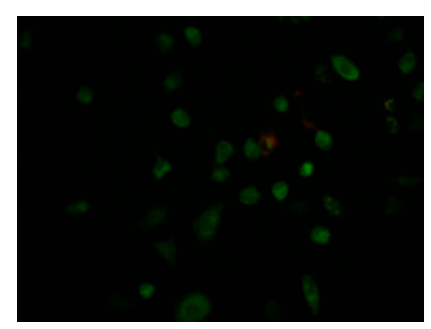

(b)

Figure 8. Investigation of the effect of compound 9n on calcium release. (a) Cells not treated with the 9n were used as control for 24 h; (b) HeLa cells treated with compound 9n for $24 \mathrm{~h}$ at $10 \mu \mathrm{M}$, respectively. 


\subsubsection{Caspase-3 Activation Assay}

It is well known that an increase of intracellular ROS can lead to apoptosis. To explore the signaling pathway involved in compound 9n induced apoptosis in HeLa cells, a decrease of mitochondria membrane potential lead to increased generation of ROS was investigated, which was known to be frequently involved in a chemically induced apoptotic signaling pathway and the resultant activation of caspase cascade [26,27]. Caspases are a family of cysteinyl aspartate specific proteases involved in apoptosis and are dichotomized to groups of initiators (caspases 8, 9 and 10) and executioners (caspases 3, 6 and 7) [28,29]. Caspase-3 is able to directly degrade multiple substrates including structural and regulatory proteins. Some small molecules have been developed to be selective activators of Caspase-3 [30]. Thus, we investigated whether caspase-3 was activated when HeLa cells were exposed to compound 9n. As shown in Figure 9a, cells treated with compound 9n had a significant increase in the activity of caspase- 3 as indicated by a notable shift in the ratio of green/dark fluorescence versus control. As shown in Figure 9b, the results clearly showed that an induction of cell apoptosis took place when the cells were treated with compound 9n, and the stimulation of caspase-3 activity both increased in a time dependent manner from 3 to $24 \mathrm{~h}$.

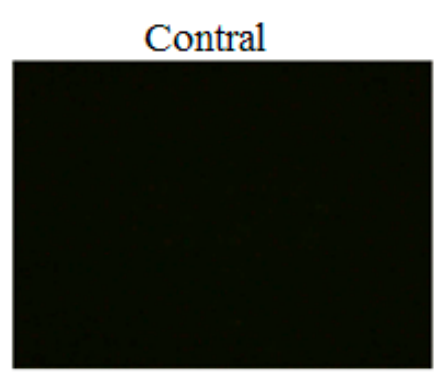

(a)

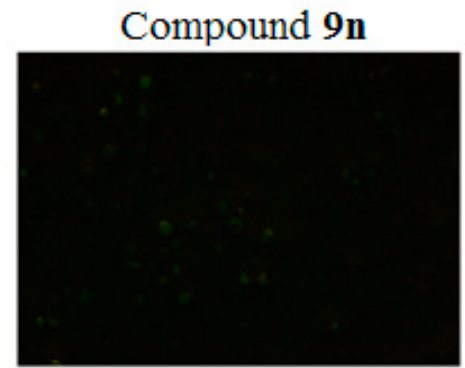

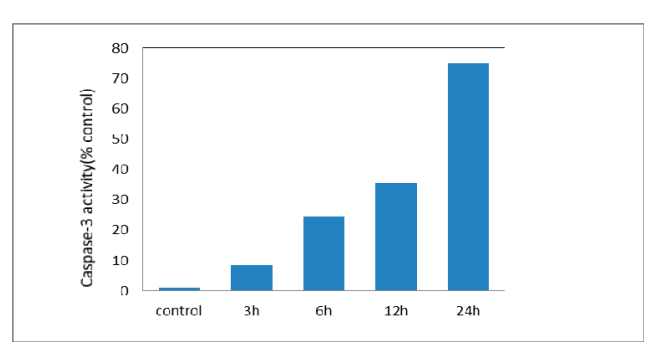

(b)

Figure 9. (a) Activation of Caspase-3 induced by compound 9n, examined by FITC-DEVD-FMK under a fluorescent microscope; (b) Measurement of caspase-3 activity. Dose-dependent induction of caspase-3 in human HeLa cell line.

\section{Experimental Section}

\subsection{Chemistry}

Experimental: NMR spectra were recorded on a BRUKER AVANCE 400 NMR spectrometer (Bruker, Rheinstetten, Germany) in $\mathrm{CDCl}_{3}$. Mass spectra were determined on a FTMS ESI spectrometer (Thermo, Waltham, MA, USA).

General procedure for the preparation of compounds 8 and 9: 1-amino acid (1 mmol) and phthalic anhydride $(1.2 \mathrm{mmol})$ were added to $\mathrm{CH}_{3} \mathrm{COOH}(25 \mathrm{~mL})$ and the mixture was stirred at $50{ }^{\circ} \mathrm{C}$ for $12 \mathrm{~h}$ to offer compound 2. Compound $2(1 \mathrm{mmol})$ added to dry $\mathrm{CH}_{2} \mathrm{Cl}_{2}(15 \mathrm{~mL})$ was stirred at $0{ }^{\circ} \mathrm{C}$ and oxalyl chloride $(1.5 \mathrm{mmol})$ was dripped into the mixture and stirred at room temperature for $6 \mathrm{~h}$. After the reaction, the solvent and excess oxalyl chloride was evaporated under reduced pressure. Aromatic primary amines $(1 \mathrm{mmol})$ and triethylamine $(0.5 \mathrm{mmol})$ were added to the mixture and stirred at room temperature for $0.5 \mathrm{~h}$. After the reaction, the solvent was evaporated under reduced pressure, and the 
crude product was purified by chromatography on silica gel eluted with petroleum ether/ethyl acetate $(V: V=6: 1)$ to offer compound 4 . Compound $4(1 \mathrm{mmol})$ and hydrazine hydrate $(3 \mathrm{mmol})$ were added to ethanol $(15 \mathrm{~mL})$ and the mixture was stirred at room temperature for $8 \mathrm{~h}$. After the reaction was completed, the solvent was evaporated under reduced pressure, and the crude product was purified by chromatography on silica gel eluted with petroleum ether/ethyl acetate $(V: V=3: 1)$ to obtain compounds 5. DHAA $(1 \mathrm{mmol})$ added to dry $\mathrm{CH}_{2} \mathrm{Cl}_{2}(15 \mathrm{~mL})$ was stirred at $0{ }^{\circ} \mathrm{C}$ and oxalyl chloride $(1.5 \mathrm{mmol})$ was dripped into the mixture and stirred at room temperature for $6 \mathrm{~h}$. After the reaction, the solvent and excess oxalyl chloride was evaporated under reduced pressure to offer compound 6. Compound $6(1 \mathrm{mmol})$ and $\mathrm{KSCN}(1.2 \mathrm{mmol})$ were added to toluene $(15 \mathrm{~mL})$ and the mixture was stirred at $110{ }^{\circ} \mathrm{C}$ for $12 \mathrm{~h}$ to offer compound 7. Compounds 5 (1 mmol) and compound 7 (1 mmol) were added to $\mathrm{CH}_{2} \mathrm{Cl}_{2}(15 \mathrm{~mL})$ and the mixture was stirred at room temperature for $0.5 \mathrm{~h}$. After the reaction, the solvent was evaporated under reduced pressure, and the crude product was purified by chromatography on silica gel eluted with petroleum ether/ethyl acetate $(V: V=6: 1)$ to offer compounds 8a-80 and 9a-9o.

(1R,4aS)-7-Isopropyl-1,4a-dimethyl-N-(((R)-1-oxo-1-(phenylamino)propan-2-yl)carbamothioyl)-1,2,3, 4,4a,9,10,10a-octahydrophenanthrene-1-carboxamide (8a). Yields 85.52\%; ${ }^{1} \mathrm{H}$ NMR (400 MHz, $\left.\mathrm{CDCl}_{3}\right): \delta 11.13(\mathrm{~d}, J=7.5 \mathrm{~Hz}, 1 \mathrm{H}, \mathrm{NH}), 8.71(\mathrm{~s}, 1 \mathrm{H}, \mathrm{NH}), 8.61(\mathrm{~s}, 1 \mathrm{H}, \mathrm{NH}), 7.58(\mathrm{~d}, J=7.6 \mathrm{~Hz}, 2 \mathrm{H})$, $7.34(\mathrm{t}, J=8.0 \mathrm{~Hz}, 2 \mathrm{H}), 7.18(\mathrm{~d}, J=8.2 \mathrm{~Hz}, 1 \mathrm{H}), 7.13(\mathrm{~s}, 1 \mathrm{H}), 7.04(\mathrm{~d}, J=6.4 \mathrm{~Hz}, 1 \mathrm{H}), 6.91(\mathrm{~s}, 1 \mathrm{H})$, 5.16-5.10 (m, 1H), 2.95-2.80 (m, 3H), $2.36(\mathrm{~d}, J=13.3 \mathrm{~Hz}, 1 \mathrm{H}), 2.10(\mathrm{~d}, J=12.5 \mathrm{~Hz}, 1 \mathrm{H}), 1.80-1.69$ $(\mathrm{m}, 5 \mathrm{H}), 1.61\left(\mathrm{~d}, J=6.9 \mathrm{~Hz}, 3 \mathrm{H}, \mathrm{CH}_{3}\right), 1.53-1.46(\mathrm{~m}, 2 \mathrm{H}), 1.36\left(\mathrm{~s}, 3 \mathrm{H}, \mathrm{CH}_{3}\right), 1.25\left(\mathrm{~s}, 6 \mathrm{H}, 2 \times \mathrm{CH}_{3}\right)$, $1.23\left(\mathrm{~s}, 3 \mathrm{H}, \mathrm{CH}_{3}\right) .{ }^{13} \mathrm{C} \mathrm{NMR}\left(100 \mathrm{MHz}, \mathrm{CDCl}_{3}\right): \delta 180.1,179.5,168.5,146.1,146.1,137.6,134.2$, 129.0, 126.9, 124.4, 124.1, 123.9, 119.9, 55.2, 48.6, 45.2, 37.6, 37.1, 37.0, 33.4, 29.7, 25.1, 23.9, 21.4, 18.4, 16.7, 16.1. HR-MS (m/z) (ESI): calcd for $\mathrm{C}_{30} \mathrm{H}_{3}{ }_{3} \mathrm{~N}_{3} \mathrm{O}_{2} \mathrm{~S}\left[\mathrm{M}-\mathrm{H}^{+}\right]$: 504.26847; found: 504.26982.

(1R,4aS)-7-Isopropyl-1,4a-dimethyl-N-(((R)-1-oxo-1-(o-tolylamino)propan-2-yl)carbamothioyl)-1,2, 3,4,4a,9,10,10a-octahydrophenanthrene-1-carboxamide (8b). Yields 84.32\%; ${ }^{1} \mathrm{H}$ NMR (400 MHz, $\left.\mathrm{CDCl}_{3}\right): \delta 11.10(\mathrm{~d}, J=7.7 \mathrm{~Hz}, 1 \mathrm{H}, \mathrm{NH}), 8.63(\mathrm{~s}, 1 \mathrm{H}, \mathrm{NH}), 8.22(\mathrm{~s}, 1 \mathrm{H}, \mathrm{NH}), 7.87(\mathrm{~d}, J=7.7 \mathrm{~Hz}, 1 \mathrm{H})$, $7.21(\mathrm{~d}, J=8.4 \mathrm{~Hz}, 1 \mathrm{H}), 7.06(\mathrm{~d}, J=8.2 \mathrm{~Hz}, 1 \mathrm{H}), 7.00(\mathrm{~d}, J=8.0 \mathrm{~Hz}, 2 \mathrm{H}), 6.88(\mathrm{~s}, 1 \mathrm{H}), 6.71-6.65(\mathrm{~m}$, $1 \mathrm{H}), 5.17-5.13(\mathrm{~m}, 1 \mathrm{H}), 2.93-2.77(\mathrm{~m}, 3 \mathrm{H}), 2.32(\mathrm{~d}, J=12.9 \mathrm{~Hz}, 1 \mathrm{H}), 2.27\left(\mathrm{~s}, 3 \mathrm{H}, \mathrm{CH}_{3}\right), 2.07(\mathrm{~d}$, $J=10.7 \mathrm{~Hz}, 1 \mathrm{H}), 1.80-1.66(\mathrm{~m}, 5 \mathrm{H}), 1.59\left(\mathrm{~d}, J=6.9 \mathrm{~Hz}, 3 \mathrm{H}, \mathrm{CH}_{3}\right), 1.50-1.42(\mathrm{~m}, 2 \mathrm{H}), 1.32(\mathrm{~s}, 3 \mathrm{H}$, $\left.\mathrm{CH}_{3}\right), 1.22\left(\mathrm{~d}, J=2.8 \mathrm{~Hz}, 6 \mathrm{H}, 2 \times \mathrm{CH}_{3}\right), 1.21\left(\mathrm{~s}, 3 \mathrm{H}, \mathrm{CH}_{3}\right) .{ }^{13} \mathrm{C} \mathrm{NMR}\left(100 \mathrm{MHz}, \mathrm{CDCl}_{3}\right): \delta 179.8$, $179.4,168.6,146.1,145.9,135.5,134.1,130.4,128.8,126.8,126.5,124.0,122.6,121.2,118.4,55.1$, $48.5,45.1,37.5,36.9,36.9,33.3,29.6,25.0,23.9,21.3,18.1,17.3,16.8,16.0$. HR-MS (m/z) (ESI): calcd for $\mathrm{C}_{31} \mathrm{H}_{41} \mathrm{~N}_{3} \mathrm{O}_{2} \mathrm{~S}\left[\mathrm{M}-\mathrm{H}^{+}\right]$: 518.28412; found: 518.28514 .

(1R,4aS)-7-Isopropyl-1,4a-dimethyl-N-(((R)-1-oxo-1-(p-tolylamino)propan-2-yl)carbamothioyl)-1,2, 3,4,4a,9,10,10a-octahydrophenanthrene-1-carboxamide (8c). Yields 81.26\%; ${ }^{1} \mathrm{H}$ NMR (400 MHz, $\left.\mathrm{CDCl}_{3}\right): \delta 11.11(\mathrm{~d}, J=7.5 \mathrm{~Hz}, 1 \mathrm{H}, \mathrm{NH}), 8.59(\mathrm{~d}, J=4.3 \mathrm{~Hz}, 2 \mathrm{H}, \mathrm{NH}), 7.43(\mathrm{~d}, J=8.4 \mathrm{~Hz}, 2 \mathrm{H}), 7.15$ $(\mathrm{d}, J=8.2 \mathrm{~Hz}, 1 \mathrm{H}), 7.10(\mathrm{~d}, J=8.2 \mathrm{~Hz}, 2 \mathrm{H}), 7.01(\mathrm{dd}, J=8.2,1.7 \mathrm{~Hz}, 1 \mathrm{H}), 6.88(\mathrm{~d}, J=1.3 \mathrm{~Hz}, 1 \mathrm{H})$, $5.08(\mathrm{dd}, J=13.5,7.3 \mathrm{~Hz}, 1 \mathrm{H}), 3.00-2.74(\mathrm{~m}, 3 \mathrm{H}), 2.33(\mathrm{~d}, J=12.3 \mathrm{~Hz}, 1 \mathrm{H}), 2.30\left(\mathrm{~s}, 3 \mathrm{H}, \mathrm{CH}_{3}\right), 2.07$ $(\mathrm{d}, J=10.6 \mathrm{~Hz}, 1 \mathrm{H}), 1.79-1.64(\mathrm{~m}, 5 \mathrm{H}), 1.58\left(\mathrm{~d}, J=6.9 \mathrm{~Hz}, 3 \mathrm{H}, \mathrm{CH}_{3}\right), 1.51-1.43(\mathrm{~m}, 2 \mathrm{H}), 1.33(\mathrm{~s}, 3 \mathrm{H}$, $\left.\mathrm{CH}_{3}\right), 1.23\left(\mathrm{~s}, 6 \mathrm{H}, 2 \times \mathrm{CH}_{3}\right), 1.21\left(\mathrm{~s}, 3 \mathrm{H}, \mathrm{CH}_{3}\right) .{ }^{13} \mathrm{C} \mathrm{NMR}\left(100 \mathrm{MHz}, \mathrm{CDCl}_{3}\right): \delta 179.8,179.4,168.4$, 146.1, 146.0, 135.0, 134.2, 134.0, 129.4, 126.9, 124.0, 123.9, 119.9, 55.2, 48.6, 45.1, 37.5, 37.0, 37.0, 
33.4, 29.6, 25.1, 23.9, 21.4, 20.8, 18.4, 16.8, 16.0. HR-MS $(m / z)(E S I)$ : calcd for $\mathrm{C}_{31} \mathrm{H}_{41} \mathrm{~N}_{3} \mathrm{O}_{2} \mathrm{~S}$ $\left[\mathrm{M}-\mathrm{H}^{+}\right]:$518.28412; found: 518.28516.

(1R,4aS)-N-(((R)-1-((2-Chlorophenyl)amino)-1-oxopropan-2-yl)carbamothioyl)-7-isopropyl-1,4adimethyl-1,2,3,4,4a,9,10,10a-octahydrophenanthrene-1-carboxamide (8d). Yields $84.16 \%$; ${ }^{1} \mathrm{H}$ NMR (400 MHz, $\left.\mathrm{CDCl}_{3}\right): \delta 11.15(\mathrm{~d}, J=7.4 \mathrm{~Hz}, 1 \mathrm{H}, \mathrm{NH}), 8.67(\mathrm{~s}, 1 \mathrm{H}, \mathrm{NH}), 8.51(\mathrm{~s}, 1 \mathrm{H}, \mathrm{NH}), 8.36$ (d, $J=8.2 \mathrm{~Hz}, 1 \mathrm{H}), 7.36(\mathrm{dd}, J=8.0,1.4 \mathrm{~Hz}, 1 \mathrm{H}), 7.26(\mathrm{~d}, J=7.2 \mathrm{~Hz}, 1 \mathrm{H}), 7.15(\mathrm{~d}, J=8.2 \mathrm{~Hz}, 1 \mathrm{H}), 7.05$ $(\mathrm{d}, J=9.1 \mathrm{~Hz}, 1 \mathrm{H}), 7.01(\mathrm{~d}, J=8.3 \mathrm{~Hz}, 1 \mathrm{H}), 6.89(\mathrm{~s}, 1 \mathrm{H}), 5.20-5.14(\mathrm{~m}, 1 \mathrm{H}), 2.92-2.79(\mathrm{~m}, 3 \mathrm{H}), 2.33$ $(\mathrm{d}, J=13.3 \mathrm{~Hz}, 1 \mathrm{H}), 2.09(\mathrm{~d}, J=12.4 \mathrm{~Hz}, 1 \mathrm{H}), 1.83-1.68(\mathrm{~m}, 5 \mathrm{H}), 1.62\left(\mathrm{~d}, J=7.0 \mathrm{~Hz}, 3 \mathrm{H}, \mathrm{CH}_{3}\right)$, $1.52-1.46(\mathrm{~m}, 2 \mathrm{H}), 1.34\left(\mathrm{~s}, 3 \mathrm{H}, \mathrm{CH}_{3}\right), 1.23\left(\mathrm{~s}, 6 \mathrm{H}, 2 \times \mathrm{CH}_{3}\right), 1.21\left(\mathrm{~s}, 3 \mathrm{H}, \mathrm{CH}_{3}\right) .{ }^{13} \mathrm{C} \mathrm{NMR}(100 \mathrm{MHz}$, $\left.\mathrm{CDCl}_{3}\right): \delta 180.0,179.4,168.7,146.0,145.9,134.1,134.1,129.0,127.5,126.8,124.9,123.9,123.9$, $123.1,121.7,55.4,48.5,45.1,37.5,36.9,36.8,33.3,29.6,25.0,23.9,21.3,18.3,17.1$, 16.0. HR-MS $(m / z)(E S I)$ : calcd for $\mathrm{C}_{30} \mathrm{H}_{38} \mathrm{ClN}_{3} \mathrm{O}_{3} \mathrm{~S}\left[\mathrm{M}-\mathrm{H}^{+}\right]$: 538.22950; found: 538.23111.

(1R,4aS)-N-(((R)-1-((4-Chlorophenyl)amino)-1-oxopropan-2-yl)carbamothioyl)-7-isopropyl-1,4adimethyl-1,2,3,4,4a,9,10,10a-octahydrophenanthrene-1-carboxamide (8e). Yields 84.78\%; ${ }^{1} \mathrm{H}$ NMR (400 MHz, $\left.\mathrm{CDCl}_{3}\right): \delta 11.10(\mathrm{~d}, J=7.5 \mathrm{~Hz}, 1 \mathrm{H}, \mathrm{NH}), 8.86(\mathrm{~s}, 1 \mathrm{H}, \mathrm{NH}), 8.60(\mathrm{~s}, 1 \mathrm{H}, \mathrm{NH}), 7.51$ (d, $J=8.9 \mathrm{~Hz}, 2 \mathrm{H}), 7.29-7.26(\mathrm{~m}, 2 \mathrm{H}), 7.15(\mathrm{~s}, 1 \mathrm{H}), 7.02(\mathrm{dd}, J=8.2,1.7 \mathrm{~Hz}, 1 \mathrm{H}), 6.89(\mathrm{~d}, J=1.4 \mathrm{~Hz}$, $1 \mathrm{H}), 5.11-5.07(\mathrm{~m}, 1 \mathrm{H}), 2.93-2.80(\mathrm{~m}, 3 \mathrm{H}), 2.34(\mathrm{~d}, J=13.3 \mathrm{~Hz}, 1 \mathrm{H}), 2.07(\mathrm{~d}, J=12.0 \mathrm{~Hz}, 1 \mathrm{H})$, 1.82-1.69 (m, 5H), $1.58\left(\mathrm{~d}, J=6.9 \mathrm{~Hz}, 3 \mathrm{H}, \mathrm{CH}_{3}\right), 1.51-1.44(\mathrm{~m}, 2 \mathrm{H}), 1.34\left(\mathrm{~s}, 3 \mathrm{H}, \mathrm{CH}_{3}\right), 1.23(\mathrm{~s}, 6 \mathrm{H}$, $\left.2 \times \mathrm{CH}_{3}\right), 1.21\left(\mathrm{~s}, 3 \mathrm{H}, \mathrm{CH}_{3}\right) .{ }^{13} \mathrm{C} \mathrm{NMR}\left(100 \mathrm{MHz}, \mathrm{CDCl}_{3}\right): \delta 180.2,179.6,168.49,146.1,146.1$, 136.2, 134.1, 129.3, 129.0, 126.9, 124.1, 123.9, 121.2, 55.1, 48.7, 45.2, 37.6, 37.1, 37.0, 33.4, 29.7, 25.1, 23.9, 21.5, 18.4, 16.5, 16.1. HR-MS (m/z) (ESI): calcd for $\mathrm{C}_{30} \mathrm{H}_{38} \mathrm{ClN}_{3} \mathrm{O}_{3} \mathrm{~S}\left[\mathrm{M}-\mathrm{H}^{+}\right]$: 538.22950; found: 538.23074 .

(1R,4aS)-7-Isopropyl-N-(((R)-1-((2-methoxyphenyl)amino)-1-oxopropan-2-yl)carbamothioyl)-1,4adimethyl-1,2,3,4,4a,9,10,10a-octahydrophenanthrene-1-carboxamide (8f). Yields $82.38 \% ;{ }^{1} \mathrm{H}$ NMR (400 MHz, $\mathrm{CDCl}_{3}$ ): $\delta 11.19$ (d, $\left.J=7.3 \mathrm{~Hz}, 1 \mathrm{H}, \mathrm{NH}\right), 8.61(\mathrm{~s}, 1 \mathrm{H}, \mathrm{NH}), 8.46(\mathrm{~s}, 1 \mathrm{H}, \mathrm{NH}), 8.37$ (dd, $J=8.0,1.5 \mathrm{~Hz}, 1 \mathrm{H}), 7.15(\mathrm{~d}, J=8.2 \mathrm{~Hz}, 1 \mathrm{H}), 7.05(\mathrm{t}, J=7.0 \mathrm{~Hz}, 1 \mathrm{H}), 7.01(\mathrm{~d}, J=9.9 \mathrm{~Hz}, 1 \mathrm{H}), 6.95(\mathrm{~d}$, $J=9.0 \mathrm{~Hz}, 1 \mathrm{H}), 6.87(\mathrm{~d}, J=9.1 \mathrm{~Hz}, 2 \mathrm{H}), 5.11(\mathrm{dd}, J=14.1,7.0 \mathrm{~Hz}, 1 \mathrm{H}), 3.87\left(\mathrm{~s}, 3 \mathrm{H}, \mathrm{OCH}_{3}\right)$, 2.97-2.77 (m, 3H), $2.33(\mathrm{~d}, J=13.3 \mathrm{~Hz}, 1 \mathrm{H}), 2.08$ (d, $J=14.3 \mathrm{~Hz}, 1 \mathrm{H}), 1.83-1.67(\mathrm{~m}, 5 \mathrm{H}), 1.62(\mathrm{~d}$, $\left.J=7.0 \mathrm{~Hz}, 3 \mathrm{H}, \mathrm{CH}_{3}\right), 1.53-1.46(\mathrm{~m}, 2 \mathrm{H}), 1.34\left(\mathrm{~s}, 3 \mathrm{H}, \mathrm{CH}_{3}\right), 1.23\left(\mathrm{~s}, 6 \mathrm{H}, 2 \times \mathrm{CH}_{3}\right), 1.21\left(\mathrm{~s}, 3 \mathrm{H}, \mathrm{CH}_{3}\right)$. ${ }^{13} \mathrm{C} \mathrm{NMR}\left(100 \mathrm{MHz}, \mathrm{CDCl}_{3}\right): \delta 179.4,179.1,168.4,147.8,146.1,145.8,134.1,127.1,126.8,124.0$, $123.9,123.8,120.9,119.7,109.9,55.6,55.5,48.4,45.0,37.5,36.9,36.8,33.3,29.6,25.0,23.9,21.3$, 18.3, 17.5, 16.0. HR-MS (m/z) (ESI): calcd for $\mathrm{C}_{31} \mathrm{H}_{41} \mathrm{~N}_{3} \mathrm{O}_{3} \mathrm{~S}\left[\mathrm{M}-\mathrm{H}^{+}\right]$: 534.27903; found: 534.28014.

(1R,4aS)-7-Isopropyl-N-(((R)-1-((4-methoxyphenyl)amino)-1-oxopropan-2-yl)carbamothioyl)-1,4adimethyl-1,2,3,4,4a,9,10,10a-octahydrophenanthrene-1-carboxamide (8g). Yields 81.32\%; ${ }^{1} \mathrm{H}$ NMR $\left(400 \mathrm{MHz}, \mathrm{CDCl}_{3}\right): \delta 11.13(\mathrm{~d}, J=7.4 \mathrm{~Hz}, 1 \mathrm{H}, \mathrm{NH}), 8.59$ (d, $\left.J=3.1 \mathrm{~Hz}, 2 \mathrm{H}, \mathrm{NH}\right), 7.46$ (d, $J=9.0 \mathrm{~Hz}$, 2H), $7.15(\mathrm{~d}, J=8.2 \mathrm{~Hz}, 1 \mathrm{H}), 7.01(\mathrm{dd}, J=8.1,1.7 \mathrm{~Hz}, 1 \mathrm{H}), 6.88(\mathrm{~d}, J=1.3 \mathrm{~Hz}, 1 \mathrm{H}), 6.84(\mathrm{~d}, J=9.0 \mathrm{~Hz}$, 2H), 5.09-5.03 (m, 1H), $3.77\left(\mathrm{~s}, 3 \mathrm{H}, \mathrm{OCH}_{3}\right), 2.94-2.80(\mathrm{~m}, 3 \mathrm{H}), 2.33(\mathrm{~d}, J=13.2 \mathrm{~Hz}, 1 \mathrm{H}), 2.07$ (dd, $J=13.0,2.3 \mathrm{~Hz}, 1 \mathrm{H}), 1.80-1.67(\mathrm{~m}, 5 \mathrm{H}), 1.58\left(\mathrm{~d}, J=6.9 \mathrm{~Hz}, 3 \mathrm{H}, \mathrm{CH}_{3}\right), 1.52-1.46(\mathrm{~m}, 2 \mathrm{H}), 1.33$ $\left(\mathrm{s}, 3 \mathrm{H}, \mathrm{CH}_{3}\right), 1.23\left(\mathrm{~s}, 6 \mathrm{H}, 2 \times \mathrm{CH}_{3}\right), 1.21\left(\mathrm{~s}, 3 \mathrm{H}, \mathrm{CH}_{3}\right) .{ }^{13} \mathrm{C} \mathrm{NMR}\left(100 \mathrm{MHz}, \mathrm{CDCl}_{3}\right): \delta 179.7,179.3$, 168.4, 156.3, 146.1, 145.9, 134.1, 130.7, 126.9, 124.0, 123.9, 121.6, 114.0, 55.4, 55.1, 48.5, 45.1, 37.5, 
36.9, 36.9, 33.4, 29.6, 25.1, 23.9, 21.4, 18.4, 16.9, 16.0. HR-MS $(m / z)(E S I)$ : calcd for $\mathrm{C}_{31} \mathrm{H}_{41} \mathrm{~N}_{3} \mathrm{O}_{3} \mathrm{~S}$ $\left[\mathrm{M}-\mathrm{H}^{+}\right]$: 534.27903; found: 534.28029.

(1R,4aS)-N-(((R)-1-((2-Fluorophenyl)amino)-1-oxopropan-2-yl)carbamothioyl)-7-isopropyl-1,4adimethyl-1,2,3,4,4a,9,10,10a-octahydrophenanthrene-1-carboxamide (8h). Yields 87.22\%; ${ }^{1} \mathrm{H}$ NMR $\left(400 \mathrm{MHz}_{\mathrm{CDCl}}\right)$ ): $\delta 11.14(\mathrm{~d}, J=7.4 \mathrm{~Hz}, 1 \mathrm{H}, \mathrm{NH}), 8.65(\mathrm{~s}, 1 \mathrm{H}, \mathrm{NH}), 8.59(\mathrm{~s}, 1 \mathrm{H}, \mathrm{NH}), 8.30(\mathrm{~s}, 1 \mathrm{H})$, $7.15(\mathrm{~d}, J=8.2 \mathrm{~Hz}, 1 \mathrm{H}), 7.13-7.06(\mathrm{~m}, 2 \mathrm{H}), 7.04(\mathrm{~s}, 1 \mathrm{H}), 7.01(\mathrm{~d}, J=8.3 \mathrm{~Hz}, 1 \mathrm{H}), 6.88(\mathrm{~s}, 1 \mathrm{H}), 5.16$ $(\mathrm{dd}, J=14.2,7.1 \mathrm{~Hz}, 1 \mathrm{H}), 2.95-2.79(\mathrm{~m}, 3 \mathrm{H}), 2.33(\mathrm{~d}, J=13.1 \mathrm{~Hz}, 1 \mathrm{H}), 2.07(\mathrm{~d}, J=1.7 \mathrm{~Hz}, 1 \mathrm{H})$, $1.82-1.66(\mathrm{~m}, 5 \mathrm{H}), 1.61\left(\mathrm{~d}, J=7.0 \mathrm{~Hz}, 3 \mathrm{H}, \mathrm{CH}_{3}\right), 1.51-1.44(\mathrm{~m}, 2 \mathrm{H}), 1.33\left(\mathrm{~s}, 3 \mathrm{H}, \mathrm{CH}_{3}\right), 1.22(\mathrm{~s}, 6 \mathrm{H}$, $\left.2 \times \mathrm{CH}_{3}\right), 1.21\left(\mathrm{~s}, 3 \mathrm{H}, \mathrm{CH}_{3}\right) \cdot{ }^{13} \mathrm{C} \mathrm{NMR}\left(100 \mathrm{MHz} \mathrm{CDCl}_{3}\right): \delta 179.9,179.4,168.8,153.6,151.1,146.0$, 145.9, 134.1, 126.8, 125.9, 125.8, 124.6, 124.5, 124.4, 124.3, 123.9, 123.8, 121.7, 121.2, 114.8, 114.6, 55.2, 48.5, 45.0, 37.4, 36.9, 36.8, 33.3, 29.6, 25.0, 23.8, 21.3, 18.3, 16.9, 16.0. HR-MS (m/z) (ESI): calcd for $\mathrm{C}_{30} \mathrm{H}_{38} \mathrm{FN}_{3} \mathrm{O}_{2} \mathrm{~S}\left[\mathrm{M}-\mathrm{H}^{+}\right]$: 522.25905; found: 522.26047.

(1R,4aS)-N-(((R)-1-((4-Fluorophenyl)amino)-1-oxopropan-2-yl)carbamothioyl)-7-isopropyl-1,4adimethyl-1,2,3,4,4a,9,10,10a-octahydrophenanthrene-1-carboxamide (8i). Yields $81.26 \%$; ${ }^{1} \mathrm{H}$ NMR (400 MHz, $\left.\mathrm{CDCl}_{3}\right): \delta 11.15$ (d, J=7.4 Hz, 1H, NH), 8.82 (s, 1H, NH), 8.63 (s, 1H, NH), 7.56-7.52 (m, $2 \mathrm{H}), 7.19(\mathrm{~d}, J=8.2 \mathrm{~Hz}, 1 \mathrm{H}), 7.06-6.99(\mathrm{~m}, 3 \mathrm{H}), 6.91(\mathrm{~d}, J=1.4 \mathrm{~Hz}, 1 \mathrm{H}), 5.14-5.07(\mathrm{~m}, 1 \mathrm{H})$, 2.96-2.82 (m, 3H), $2.36(\mathrm{~d}, J=13.3 \mathrm{~Hz}, 1 \mathrm{H}), 2.11(\mathrm{~s}, 1 \mathrm{H}), 1.84-1.66(\mathrm{~m}, 5 \mathrm{H}), 1.61(\mathrm{~d}, J=6.9 \mathrm{~Hz}, 3 \mathrm{H}$, $\left.\mathrm{CH}_{3}\right), 1.56-1.47(\mathrm{~m}, 2 \mathrm{H}), 1.36\left(\mathrm{~s}, 3 \mathrm{H}, \mathrm{CH}_{3}\right), 1.26\left(\mathrm{~s}, 6 \mathrm{H}, 2 \times \mathrm{CH}_{3}\right), 1.24\left(\mathrm{~s}, 3 \mathrm{H}, \mathrm{CH}_{3}\right) .{ }^{13} \mathrm{C} \mathrm{NMR}(100 \mathrm{MHz}$, $\left.\mathrm{CDCl}_{3}\right): \delta 178.0,179.5,168.6,160.5,158.1,146.1,146.0,134.1,133.6,133.6,126.9,124.0,123.9$, 121.7, 121.6, 115.7, 115.4, 55.1, 48.6, 45.1, 37.5, 37.0, 36.9, 33.4, 29.6, 25.1, 23.9, 21.4, 18.4, 16.8, 16.0. HR-MS $(\mathrm{m} / \mathrm{z})(\mathrm{ESI})$ : calcd for $\mathrm{C}_{30} \mathrm{H}_{38} \mathrm{FN}_{3} \mathrm{O}_{2} \mathrm{~S}\left[\mathrm{M}-\mathrm{H}^{+}\right]$: 522.25905; found: 522.26019.

(1R,4aS)-N-(((R)-1-((2-Bromophenyl)amino)-1-oxopropan-2-yl)carbamothioyl)-7-isopropyl-1,4adimethyl-1,2,3,4,4a,9,10,10a-octahydrophenanthrene-1-carboxamide $(\mathbf{8 j})$. Yields $83.16 \% ;{ }^{1} \mathrm{H}$ NMR $\left(400 \mathrm{MHz}, \mathrm{CDCl}_{3}\right): \delta 11.17(\mathrm{~d}, J=7.3 \mathrm{~Hz}, 1 \mathrm{H}, \mathrm{NH}), 8.69(\mathrm{~s}, 1 \mathrm{H}, \mathrm{NH}), 8.41(\mathrm{~s}, 1 \mathrm{H}, \mathrm{NH}), 8.35$ (d, $J=8.3 \mathrm{~Hz}, 1 \mathrm{H}), 7.56(\mathrm{~d}, J=9.4 \mathrm{~Hz}, 1 \mathrm{H}), 7.33(\mathrm{t}, J=8.5 \mathrm{~Hz}, 1 \mathrm{H}), 7.18(\mathrm{~d}, J=8.2 \mathrm{~Hz}, 1 \mathrm{H}), 7.06-6.99$ $(\mathrm{m}, 2 \mathrm{H}), 6.91(\mathrm{~s}, 1 \mathrm{H}), 5.21-5.15(\mathrm{~m}, 1 \mathrm{H}), 2.96-2.81(\mathrm{~m}, 3 \mathrm{H}), 2.36(\mathrm{~d}, J=13.4 \mathrm{~Hz}, 1 \mathrm{H}), 2.12(\mathrm{~d}$, $J=12.5 \mathrm{~Hz}, 1 \mathrm{H}), 1.85-1.70(\mathrm{~m}, 5 \mathrm{H}), 1.66\left(\mathrm{~d}, J=7.0 \mathrm{~Hz}, 3 \mathrm{H}, \mathrm{CH}_{3}\right), 1.55-1.48(\mathrm{~m}, 2 \mathrm{H}), 1.37(\mathrm{~s}, 3 \mathrm{H}$, $\left.\mathrm{CH}_{3}\right), 1.25\left(\mathrm{~s}, 6 \mathrm{H}, 2 \times \mathrm{CH}_{3}\right), 1.23\left(\mathrm{~s}, 3 \mathrm{H}, \mathrm{CH}_{3}\right) .{ }^{13} \mathrm{C} \mathrm{NMR}\left(100 \mathrm{MHz}, \mathrm{CDCl}_{3}\right): \delta 180.1,179.5,168.8$, $146.1,146.0,135.2,134.1,132.3,128.2,126.9,125.5,124.0,123.9,122.1,113.7,55.6,48.6,45.2$, $37.5,37.0,36.9,33.4,29.7,25.1,23.9,21.4,18.4,17.3,16.1$. HR-MS $(\mathrm{m} / z)$ (ESI): calcd for $\mathrm{C}_{30} \mathrm{H}_{38} \mathrm{BrN}_{3} \mathrm{O}_{2} \mathrm{~S}\left[\mathrm{M}+\mathrm{H}^{+}\right.$]: 584.19464; found: 584.19453 .

(1R,4aS)-N-(((R)-1-((4-Bromophenyl)amino)-1-oxopropan-2-yl)carbamothioyl)-7-isopropyl-1,4adimethyl-1,2,3,4,4a,9,10,10a-octahydrophenanthrene-1-carboxamide (8k). Yields 82.19\%; ${ }^{1} \mathrm{H}$ NMR $\left(400 \mathrm{MHz}, \mathrm{CDCl}_{3}\right): \delta 11.10(\mathrm{~d}, J=7.5 \mathrm{~Hz}, 1 \mathrm{H}, \mathrm{NH}), 8.81(\mathrm{~s}, 1 \mathrm{H}, \mathrm{NH}), 8.63(\mathrm{~s}, 1 \mathrm{H}, \mathrm{NH}), 7.43$ (d, $J=7.3 \mathrm{~Hz}, 2 \mathrm{H}), 7.15(\mathrm{~d}, J=8.2 \mathrm{~Hz}, 1 \mathrm{H}), 7.01(\mathrm{~d}, J=8.2 \mathrm{~Hz}, 1 \mathrm{H}), 6.88(\mathrm{~s}, 1 \mathrm{H}), 6.55(\mathrm{~s}, 2 \mathrm{H})$, 5.10-5.05 (m, 1H), 2.92-2.78 (m, 3H), $2.33(\mathrm{~d}, J=13.3 \mathrm{~Hz}, 1 \mathrm{H}), 2.06(\mathrm{~d}, J=12.5 \mathrm{~Hz}, 1 \mathrm{H}), 1.81-1.65$ $(\mathrm{m}, 5 \mathrm{H}), 1.57(\mathrm{~d}, J=6.9 \mathrm{~Hz}, 3 \mathrm{H}, \mathrm{CH} 3), 1.49-1.42(\mathrm{~m}, 2 \mathrm{H}), 1.32\left(\mathrm{~s}, 3 \mathrm{H}, \mathrm{CH}_{3}\right), 1.22(\mathrm{~d}, J=3.1 \mathrm{~Hz}$, $\left.6 \mathrm{H}, 2 \times \mathrm{CH}_{3}\right), 1.21\left(\mathrm{~s}, 3 \mathrm{H}, \mathrm{CH}_{3}\right) .{ }^{13} \mathrm{C} \mathrm{NMR}\left(100 \mathrm{MHz}, \mathrm{CDCl}_{3}\right): \delta 180.1,179.6,168.5,146.1,145.3$, $136.7,134.1,131.1,127.0,123.9,121.5,116.6,110.1,55.1,48.6,45.1,37.5,37.0,36.9,33.4,29.6$, 
25.1, 23.9, 21.4, 18.4, 16.5, 16.0. HR-MS (m/z) (ESI): calcd for $\mathrm{C}_{30} \mathrm{H}_{38} \mathrm{BrN}_{3} \mathrm{O}_{2} \mathrm{~S}\left[\mathrm{M}+\mathrm{H}^{+}\right]$: 584.19464; found: 584.19565 .

(1R,4aS)-N-(((R)-1-((3,5-Dimethylphenyl)amino)-1-oxopropan-2-yl)carbamothioyl)-7-isopropyl-1,4adimethyl-1,2,3,4,4a,9,10,10a-octahydrophenanthrene-1-carboxamide (81). Yields $80.25 \%$; ${ }^{1} \mathrm{H}$ NMR (400 MHz, $\left.\mathrm{CDCl}_{3}\right): \delta 11.11(\mathrm{~d}, J=7.5 \mathrm{~Hz}, 1 \mathrm{H}, \mathrm{NH}), 8.59$ (s, 1H, NH), $8.54(\mathrm{~s}, 1 \mathrm{H}, \mathrm{NH}), 7.19$ (s, 2H), $7.15(\mathrm{~d}, J=8.2 \mathrm{~Hz}, 1 \mathrm{H}), 7.00(\mathrm{~d}, J=9.6 \mathrm{~Hz}, 1 \mathrm{H}), 6.88(\mathrm{~s}, 1 \mathrm{H}), 6.74(\mathrm{~s}, 1 \mathrm{H}), 5.07$ (dd, $J=13.1,6.0 \mathrm{~Hz}$, $1 \mathrm{H}), 2.94-2.78(\mathrm{~m}, 3 \mathrm{H}), 2.33(\mathrm{~d}, J=13.2 \mathrm{~Hz}, 1 \mathrm{H}), 2.27\left(\mathrm{~s}, 6 \mathrm{H}, 2 \times \mathrm{CH}_{3}\right), 2.07(\mathrm{~d}, J=14.2 \mathrm{~Hz}, 1 \mathrm{H})$, $1.83-1.74(\mathrm{~m}, 5 \mathrm{H}), 1.58\left(\mathrm{~d}, J=6.9 \mathrm{~Hz}, 3 \mathrm{H}, \mathrm{CH}_{3}\right), 1.52-1.45(\mathrm{~m}, 2 \mathrm{H}), 1.33\left(\mathrm{~s}, 3 \mathrm{H}, \mathrm{CH}_{3}\right), 1.22(\mathrm{~s}, 6 \mathrm{H}$, $\left.2 \times \mathrm{CH}_{3}\right), 1.21\left(\mathrm{~s}, 3 \mathrm{H}, \mathrm{CH}_{3}\right) .{ }^{13} \mathrm{C} \mathrm{NMR}\left(100 \mathrm{MHz}, \mathrm{CDCl}_{3}\right): \delta 179.5,179.2,168.7,146.0,145.7,138.4$, 137.3, 134.0, 126.7, 126.0, 123.8, 123.7, 117.6, 55.2, 53.3, 48.4, 44.9, 37.4, 36.8, 36.7, 33.2, 29.5, 24.9, 23.8, 21.1, 17.0, 15.8, 15.7. HR-MS (m/z) (ESI): calcd for $\mathrm{C}_{32} \mathrm{H}_{43} \mathrm{~N}_{3} \mathrm{O}_{2} \mathrm{~S}\left[\mathrm{M}-\mathrm{H}^{+}\right]$: 532.29977 ; found: 532.30120 .

(1R,4aS)-7-Isopropyl-1,4a-dimethyl-N-(((R)-1-(naphthalen-1-ylamino)-1-oxopropan-2-yl)carbamothioyl)1,2,3,4,4a,9,10,10a-octahydrophenanthrene-1-carboxamide $\mathbf{( 8 m})$. Yields 88.15\%; ${ }^{1} \mathrm{H}$ NMR (400 MHz, $\left.\mathrm{CDCl}_{3}\right): \delta 11.18(\mathrm{~d}, J=7.6 \mathrm{~Hz}, 1 \mathrm{H}, \mathrm{NH}), 8.97(\mathrm{~s}, 1 \mathrm{H}, \mathrm{NH}), 8.66(\mathrm{~s}, 1 \mathrm{H}, \mathrm{NH}), 8.00(\mathrm{~d}$, $J=7.7 \mathrm{~Hz}, 2 \mathrm{H}), 7.82(\mathrm{~d}, J=8.5 \mathrm{~Hz}, 1 \mathrm{H}), 7.65(\mathrm{~d}, J=8.2 \mathrm{~Hz}, 1 \mathrm{H}), 7.50(\mathrm{~d}, J=6.8 \mathrm{~Hz}, 1 \mathrm{H}), 7.47$ (d, $J=6.2 \mathrm{~Hz}, 1 \mathrm{H}), 7.43(\mathrm{~d}, J=7.9 \mathrm{~Hz}, 1 \mathrm{H}), 7.14(\mathrm{~d}, J=8.2 \mathrm{~Hz}, 1 \mathrm{H}), 7.01(\mathrm{~d}, J=9.8 \mathrm{~Hz}, 1 \mathrm{H}), 6.87$ (s, $1 \mathrm{H}), 5.34-5.27(\mathrm{~m}, 1 \mathrm{H}), 2.91-2.79(\mathrm{~m}, 3 \mathrm{H}), 2.32(\mathrm{~d}, J=13.0 \mathrm{~Hz}, 1 \mathrm{H}), 2.07(\mathrm{~d}, J=12.4 \mathrm{~Hz}, 1 \mathrm{H})$, 1.85-1.69 (m, 5H), $1.66\left(\mathrm{~d}, J=6.9 \mathrm{~Hz}, 3 \mathrm{H}, \mathrm{CH}_{3}\right), 1.50-1.43(\mathrm{~m}, 2 \mathrm{H}), 1.32\left(\mathrm{~s}, 3 \mathrm{H}, \mathrm{CH}_{3}\right), 1.22(\mathrm{~s}, 3 \mathrm{H}$, $\left.\mathrm{CH}_{3}\right), 1.21\left(\mathrm{~d}, J=1.8 \mathrm{~Hz}, 6 \mathrm{H}, 2 \times \mathrm{CH}_{3}\right) .{ }^{13} \mathrm{C} \mathrm{NMR}\left(100 \mathrm{MHz}, \mathrm{CDCl}_{3}: \delta 179.9,179.5,169.2,146.1\right.$, $145.9,134.1,133.9,132.2,128.5,126.9,126.6,126.2,125.9,125.6,125.5,124.0,123.9,121.1,120.2$, 55.2, 48.5, 45.0, 37.5, 36.9, 36.9, 33.4, 29.6, 25.1, 23.9, 21.4, 18.4, 16.8, 16.0. HR-MS (m/z) (ESI): calcd for $\mathrm{C}_{34} \mathrm{H}_{41} \mathrm{~N}_{3} \mathrm{O}_{2} \mathrm{~S}\left[\mathrm{M}-\mathrm{H}^{+}\right]$: 554.28412; found: 554.28545 .

(1R,4aS)-7-Isopropyl-1,4a-dimethyl-N-(((R)-1-oxo-1-(pyridin-2-ylamino)propan-2-yl)carbamothioyl)1,2,3,4,4a,9,10,10a-octahydrophenanthrene-1-carboxamide $(\mathbf{8 n})$. Yields 81.03\%; ${ }^{1} \mathrm{H}$ NMR (400 MHz, $\left.\mathrm{CDCl}_{3}\right): \delta 11.16(\mathrm{~s}, 1 \mathrm{H}, \mathrm{NH}), 9.37(\mathrm{~s}, 1 \mathrm{H}, \mathrm{NH}), 8.63(\mathrm{~s}, 1 \mathrm{H}, \mathrm{NH}), 8.35(\mathrm{~s}, 1 \mathrm{H}), 8.23(\mathrm{~d}, J=8.2 \mathrm{~Hz}, 1 \mathrm{H})$, $7.71(\mathrm{~d}, J=6.6 \mathrm{~Hz}, 1 \mathrm{H}), 7.15(\mathrm{~d}, J=8.2 \mathrm{~Hz}, 1 \mathrm{H}), 7.08(\mathrm{~d}, J=5.1 \mathrm{~Hz}, 1 \mathrm{H}), 7.01(\mathrm{~d}, J=8.1 \mathrm{~Hz}, 1 \mathrm{H})$, $6.88(\mathrm{~s}, 1 \mathrm{H}), 5.09(\mathrm{dd}, J=12.2,5.3 \mathrm{~Hz}, 1 \mathrm{H}), 2.94-2.79(\mathrm{~m}, 3 \mathrm{H}), 2.34(\mathrm{~d}, J=13.4 \mathrm{~Hz}, 1 \mathrm{H}), 2.08(\mathrm{~d}$, $J=10.6 \mathrm{~Hz}, 1 \mathrm{H}), 1.88-1.70(\mathrm{~m}, 5 \mathrm{H}), 1.60\left(\mathrm{~d}, J=7.2 \mathrm{~Hz}, 3 \mathrm{H}, \mathrm{CH}_{3}\right), 1.52-1.46(\mathrm{~m}, 2 \mathrm{H}), 1.34(\mathrm{~s}, 3 \mathrm{H}$, $\left.\mathrm{CH}_{3}\right), 1.23\left(\mathrm{~d}, J=2.7 \mathrm{~Hz}, 6 \mathrm{H}, 2 \times \mathrm{CH}_{3}\right), 1.21\left(\mathrm{~s}, 3 \mathrm{H}, \mathrm{CH}_{3}\right) .{ }^{13} \mathrm{C} \mathrm{NMR}\left(100 \mathrm{MHz}, \mathrm{CDCl}_{3}\right): \delta 180.1$, $179.4,169.5,151.1,147.8,146.2,146.0,138.5,134.2,126.9,124.0,123.9,120.1,114.5,55.6,53.4$, 48.6, 45.1, 37.6, 37.0, 33.4, 29.6, 25.1, 23.9, 21.4, 18.4, 17.5, 16.1. HR-MS ( $\mathrm{m} / \mathrm{z})$ (ESI): calcd for $\mathrm{C}_{29} \mathrm{H}_{38} \mathrm{~N}_{4} \mathrm{O}_{2} \mathrm{~S}\left[\mathrm{M}-\mathrm{H}^{+}\right]$: 505.26372; found: 505.26356.

(1R,4aS)-7-Isopropyl-1,4a-dimethyl-N-(((R)-1-oxo-1-((3,4,5-trimethoxyphenyl)amino)propan-2-yl) carbamothioyl)-1,2,3,4,4a,9,10,10a-octahydrophenanthrene-1-carboxamide (8o). Yields 82.06\%; ${ }^{1} \mathrm{H}$ NMR (400 MHz, $\left.\mathrm{CDCl}_{3}\right): \delta 11.12(\mathrm{~d}, J=7.5 \mathrm{~Hz}, 1 \mathrm{H}, \mathrm{NH}), 8.72(\mathrm{~s}, 1 \mathrm{H}, \mathrm{NH}), 8.59(\mathrm{~s}, 1 \mathrm{H}, \mathrm{NH})$, $7.16(\mathrm{~d}, J=8.2 \mathrm{~Hz}, 1 \mathrm{H}), 7.01(\mathrm{~d}, J=8.2 \mathrm{~Hz}, 1 \mathrm{H}), 6.88(\mathrm{~s}, 3 \mathrm{H}), 5.07(\mathrm{dd}, J=14.2,7.0 \mathrm{~Hz}, 1 \mathrm{H}), 3.84$ $\left(\mathrm{s}, 6 \mathrm{H}, 2 \times \mathrm{OCH}_{3}\right), 3.81\left(\mathrm{~s}, 3 \mathrm{H}, \mathrm{OCH}_{3}\right), 2.94-2.79(\mathrm{~m}, 3 \mathrm{H}), 2.34(\mathrm{~d}, J=13.3 \mathrm{~Hz}, 1 \mathrm{H}), 2.07(\mathrm{dd}$, $J=12.5,1.7 \mathrm{~Hz}, 1 \mathrm{H}), 1.85-1.66(\mathrm{~m}, 5 \mathrm{H}), 1.59$ (d, $\left.J=6.9 \mathrm{~Hz}, 3 \mathrm{H}, \mathrm{CH}_{3}\right), 1.52-1.45(\mathrm{~m}, 2 \mathrm{H}), 1.34$ $\left(\mathrm{s}, 3 \mathrm{H}, \mathrm{CH}_{3}\right), 1.23\left(\mathrm{~s}, 6 \mathrm{H}, 2 \times \mathrm{CH}_{3}\right), 1.21\left(\mathrm{~s}, 3 \mathrm{H}, \mathrm{CH}_{3}\right) .{ }^{13} \mathrm{C} \mathrm{NMR}\left(100 \mathrm{MHz}, \mathrm{CDCl}_{3}\right): \delta 179.9,179.5$, 
$168.5,153.2,146.1,146.0,134.5,134.1,133.8,126.9,124.0,123.9,97.3,60.9,56.0,55.2,48.6,45.1$, $37.5,37.0,36.9,33.4,29.6,25.1,23.9,21.4,18.4,16.7,16.0$. HR-MS $(\mathrm{m} / z)$ (ESI): calcd for $\mathrm{C}_{33} \mathrm{H}_{45} \mathrm{~N}_{3} \mathrm{O}_{5} \mathrm{~S}\left[\mathrm{M}-\mathrm{H}^{+}\right]$: 594.30016; found: 594.30143.

(1R,4aS)-7-Isopropyl-1,4a-dimethyl-N-(((R)-1-oxo-3-phenyl-1-(phenylamino)propan-2-yl)carbamothioyl)1,2,3,4,4a,9,10,10a-octahydrophenanthrene-1-carboxamide (9a). Yields 89.23\%, ${ }^{1} \mathrm{H}$ NMR (400 MHz, $\left.\mathrm{CDCl}_{3}\right): \delta 11.29(\mathrm{~d}, J=7.4 \mathrm{~Hz}, 1 \mathrm{H}, \mathrm{NH}), 8.56(\mathrm{~s}, 1 \mathrm{H}, \mathrm{NH}), 7.92(\mathrm{~s}, 1 \mathrm{H}), 7.35(\mathrm{~d}, J=7.6 \mathrm{~Hz}, 2 \mathrm{H})$, $7.30-7.28(\mathrm{~m}, 3 \mathrm{H}), 7.23(\mathrm{~s}, 2 \mathrm{H}), 7.21(\mathrm{~s}, 1 \mathrm{H}), 7.13(\mathrm{~d}, J=8.2 \mathrm{~Hz}, 1 \mathrm{H}), 7.05(\mathrm{~d}, J=7.4 \mathrm{~Hz}, 1 \mathrm{H}), 7.00$ $(\mathrm{d}, J=8.2 \mathrm{~Hz}, 1 \mathrm{H}), 6.87(\mathrm{~s}, 1 \mathrm{H}), 5.20(\mathrm{dd}, J=14.2,7.6 \mathrm{~Hz}, 1 \mathrm{H}) .3 .41-3.35(\mathrm{~m}, 1 \mathrm{H}), 3.24-3.19$ (m, $1 \mathrm{H}), 2.89-2.78(\mathrm{~m}, 3 \mathrm{H}), 2.30(\mathrm{~d}, J=13.2 \mathrm{~Hz}, 1 \mathrm{H}), 2.01$ (d, $J=12.5 \mathrm{~Hz}, 1 \mathrm{H}), 1.76-1.39(\mathrm{~m}, 7 \mathrm{H}), 1.27$ $\left(\mathrm{s}, 3 \mathrm{H}, \mathrm{CH}_{3}\right), 1.21$ (d, $\left.J=6.9 \mathrm{~Hz}, 6 \mathrm{H}, 2 \times \mathrm{CH}_{3}\right), 1.19\left(\mathrm{~s}, 3 \mathrm{H}, \mathrm{CH}_{3}\right) .{ }^{13} \mathrm{C} \mathrm{NMR}\left(100 \mathrm{MHz}, \mathrm{CDCl}_{3}\right)$ : $\delta 179.5,178.9,167.4,146.0,145.6,136.9,135.9,133.9,129.2,128.6,128.4,126.9,126.7,124.3$, 123.8, 123.7, 119.9, 61.2, 48.2, 44.9, 37.4, 37.3, 36.7, 36.5, 33.2, 29.4, 24.8, 23.7, 21.0, 18.2, 15.7. HR-MS (m/z) (ESI): calcd for $\mathrm{C}_{36} \mathrm{H}_{43} \mathrm{~N}_{3} \mathrm{O}_{2} \mathrm{~S}\left[\mathrm{M}-\mathrm{H}^{+}\right]$: 580.29977 ; found: 580.30102.

(1R,4aS)-7-Isopropyl-1,4a-dimethyl-N-(((R)-1-oxo-3-phenyl-1-(o-tolylamino)propan-2-yl)carbamothioyl)1,2,3,4,4a,9,10,10a-octahydrophenanthrene-1-carboxamide (9b). Yields 88.24\%, ${ }^{1} \mathrm{H}$ NMR (400 MHz, $\mathrm{CDCl}_{3}$ ): $\delta 11.27$ (d, $\left.J=7.5 \mathrm{~Hz}, 1 \mathrm{H}, \mathrm{NH}\right), 8.59$ (s, 1H, NH), 7.87 (d, $\left.J=8.0 \mathrm{~Hz}, 1 \mathrm{H}\right), 7.53(\mathrm{~s}, 1 \mathrm{H}), 7.32$ $(\mathrm{d}, J=9.8 \mathrm{~Hz}, 4 \mathrm{H}), 7.15(\mathrm{~d}, J=8.2 \mathrm{~Hz}, 2 \mathrm{H}), 7.10(\mathrm{~d}, J=6.8 \mathrm{~Hz}, 1 \mathrm{H}), 7.01(\mathrm{~d}, J=8.4 \mathrm{~Hz}, 2 \mathrm{H}), 6.88$ $(\mathrm{d}, J=1.4 \mathrm{~Hz}, 1 \mathrm{H}), 5.26(\mathrm{dd}, J=14.5,8.1 \mathrm{~Hz}, 1 \mathrm{H}), 3.42-3.35(\mathrm{~m}, 1 \mathrm{H}), 3.29-3.22(\mathrm{~m}, 1 \mathrm{H}), 2.90-2.79$ $(\mathrm{m}, 3 \mathrm{H}), 2.33(\mathrm{~d}, J=13.3 \mathrm{~Hz}, 1 \mathrm{H}), 2.06(\mathrm{~d}, J=12.5 \mathrm{~Hz}, 1 \mathrm{H}), 1.98\left(\mathrm{~s}, 3 \mathrm{H}, \mathrm{CH}_{3}\right), 1.75-1.45(\mathrm{~m}, 7 \mathrm{H})$, $1.32\left(\mathrm{~s}, 3 \mathrm{H}, \mathrm{CH}_{3}\right), 1.22\left(\mathrm{~d}, J=3.5 \mathrm{~Hz}, 6 \mathrm{H}, 2 \times \mathrm{CH}_{3}\right), 1.21\left(\mathrm{~s}, 3 \mathrm{H}, \mathrm{CH}_{3}\right) .{ }^{13} \mathrm{C} \mathrm{NMR}\left(100 \mathrm{MHz}, \mathrm{CDCl}_{3}\right)$ : $\delta 179.9,179.1,167.4,157.5,146.1,145.9,136.1,135.2,134.1,130.2,129.2,128.7,127.1,126.8$, $126.5,125.0,123.8,122.3,121.2,61.3,48.4,45.1,37.5,37.3,36.9,36.7,33.3,29.6,25.0,23.8,21.2$, 18.3, 17.5, 15.9. HR-MS (m/z) (ESI): calcd for $\mathrm{C}_{37} \mathrm{H}_{45} \mathrm{~N}_{3} \mathrm{O}_{2} \mathrm{~S}\left[\mathrm{M}-\mathrm{H}^{+}\right]$: 618.31302; found: 618.31195 .

(1R,4aS)-7-Isopropyl-1,4a-dimethyl-N-(((R)-1-oxo-3-phenyl-1-(p-tolylamino)propan-2-yl)carbamothioyl)1,2,3,4,4a,9,10,10a-octahydrophenanthrene-1-carboxamide (9c). Yields 87.14\%, ${ }^{1} \mathrm{H}$ NMR (400 MHz, $\left.\mathrm{CDCl}_{3}\right): \delta 11.28(\mathrm{~d}, J=7.4 \mathrm{~Hz}, 1 \mathrm{H}, \mathrm{NH}), 8.56(\mathrm{~s}, 1 \mathrm{H}, \mathrm{NH}), 7.63(\mathrm{~s}, 1 \mathrm{H}), 7.32(\mathrm{~d}, J=4.8 \mathrm{~Hz}, 4 \mathrm{H}), 7.23$ $(\mathrm{d}, J=8.5 \mathrm{~Hz}, 2 \mathrm{H}), 7.15(\mathrm{~d}, J=8.2 \mathrm{~Hz}, 1 \mathrm{H}), 7.06(\mathrm{~d}, J=8.2 \mathrm{~Hz}, 2 \mathrm{H}), 7.01(\mathrm{dd}, J=8.1,1.7 \mathrm{~Hz}, 1 \mathrm{H})$, $6.88(\mathrm{~d}, J=1.3 \mathrm{~Hz}, 1 \mathrm{H}), 5.16(\mathrm{dd}, J=14.3,7.8 \mathrm{~Hz}, 1 \mathrm{H}), 3.42-3.36(\mathrm{~m}, 1 \mathrm{H}), 3.23-3.17(\mathrm{~m}, 1 \mathrm{H})$, 2.90-2.79 (m, 3H), $2.28\left(\mathrm{~s}, 3 \mathrm{H}, \mathrm{CH}_{3}\right), 2.03(\mathrm{~d}, J=1.9 \mathrm{~Hz}, 1 \mathrm{H}), 1.76-1.45(\mathrm{~m}, 7 \mathrm{H}), 1.31\left(\mathrm{~s}, 3 \mathrm{H}, \mathrm{CH}_{3}\right)$, $1.23\left(\mathrm{~d}, J=4.1 \mathrm{~Hz}, 6 \mathrm{H}, 2 \times \mathrm{CH}_{3}\right), 1.21\left(\mathrm{~s}, 3 \mathrm{H}, \mathrm{CH}_{3}\right) .{ }^{13} \mathrm{C} \mathrm{NMR}\left(100 \mathrm{MHz}, \mathrm{CDCl}_{3}\right): \delta 179.8,179.1$, $167.2,146.2,145.9,136.3,136.2,134.5,134.1,129.3,128.7,127.1,126.9,124.0,123.9,120.1,119.8$, $61.4,48.5,45.2,37.6,37.5,37.0,36.8,33.4,29.6,25.0,23.9,21.2,20.8,18.4,16.0$. HR-MS $(\mathrm{m} / \mathrm{z})$ (ESI): calcd for $\mathrm{C}_{37} \mathrm{H}_{45} \mathrm{~N}_{3} \mathrm{O}_{2} \mathrm{~S}\left[\mathrm{M}-\mathrm{H}^{+}\right]$: 594.31542; found: 594.31687.

(1R,4aS)-N-(((R)-1-((2-Chlorophenyl)amino)-1-oxo-3-phenylpropan-2-yl)carbamothioyl)-7-isopropyl1,4a-dimethyl-1,2,3,4,4a,9,10,10a-octahydrophenanthrene-1-carboxamide (9d). Yields 82.46\%, ${ }^{1} \mathrm{H}$ NMR (400 MHz, $\left.\mathrm{CDCl}_{3}\right): \delta 11.29$ (d, $\left.J=7.4 \mathrm{~Hz}, 1 \mathrm{H}, \mathrm{NH}\right), 8.62(\mathrm{~s}, 1 \mathrm{H}, \mathrm{NH}), 8.37$ (d, $J=8.3 \mathrm{~Hz}$, $1 \mathrm{H}, \mathrm{NH}), 8.00(\mathrm{~s}, 1 \mathrm{H}), 7.30(\mathrm{~d}, J=6.0 \mathrm{~Hz}, 4 \mathrm{H}), 7.27(\mathrm{~d}, J=1.4 \mathrm{~Hz}, 1 \mathrm{H}), 7.25-7.21(\mathrm{~m}, 2 \mathrm{H}), 7.15(\mathrm{~d}$, $J=8.2 \mathrm{~Hz}, 1 \mathrm{H}), 7.03-6.98(\mathrm{~m}, 2 \mathrm{H}), 6.88(\mathrm{~d}, J=1.4 \mathrm{~Hz}, 1 \mathrm{H}), 5.29(\mathrm{dd}, J=14.2,7.5 \mathrm{~Hz}, 1 \mathrm{H})$, 3.43-3.37 (m, 1H), 3.28-3.21 (m, 1H), 2.91-2.79 (m, 3H), $2.33(\mathrm{~d}, J=13.1 \mathrm{~Hz}, 1 \mathrm{H}), 2.07(\mathrm{~d}, J=10.6 \mathrm{~Hz}$, $1 \mathrm{H}), 1.77-1.39(\mathrm{~m}, 7 \mathrm{H}), 1.32\left(\mathrm{~s}, 3 \mathrm{H}, \mathrm{CH}_{3}\right), 1.22\left(\mathrm{~d}, J=4.0 \mathrm{~Hz}, 6 \mathrm{H}, 2 \times \mathrm{CH}_{3}\right), 1.21\left(\mathrm{~s}, 3 \mathrm{H}, \mathrm{CH}_{3}\right)$. 
${ }^{13} \mathrm{C} \mathrm{NMR}\left(100 \mathrm{MHz}, \mathrm{CDCl}_{3}\right): \delta 180.0,179.1,167.5,146.1,145.7,135.7,134.0,133.9,129.1,128.8$, $128.7,127.4,127.1,126.5,124.8,123.9,123.8,122.8,121.5,61.5,48.4,45.1,37.5,37.4,36.8,36.7$, $33.3,29.5,24.9,23.8,21.2,18.3,15.9$. HR-MS $(\mathrm{m} / z)(\mathrm{ESI})$ : calcd for $\mathrm{C}_{36} \mathrm{H}_{42} \mathrm{ClN}_{3} \mathrm{O}_{2} \mathrm{~S}\left[\mathrm{M}+\mathrm{Na}^{+}\right]$: 638.25840; found: 638.25879 .

(1R,4aS)-N-(((R)-1-((4-Chlorophenyl)amino)-1-oxo-3-phenylpropan-2-yl)carbamothioyl)-7-isopropyl1,4a-dimethyl-1,2,3,4,4a,9,10,10a-octahydrophenanthrene-1-carboxamide (9e). Yields 85.78\%, ${ }^{1} \mathrm{H} \mathrm{NMR}$ $\left(400 \mathrm{MHz}, \mathrm{CDCl}_{3}\right): \delta 11.27(\mathrm{~d}, J=7.4 \mathrm{~Hz}, 1 \mathrm{H}, \mathrm{NH}), 8.56(\mathrm{~s}, 1 \mathrm{H}, \mathrm{NH}), 7.86(\mathrm{~s}, 1 \mathrm{H}), 7.32(\mathrm{~s}, 1 \mathrm{H}), 7.31$ (s, 3H), $7.29(\mathrm{~d}, J=3.3 \mathrm{~Hz}, 2 \mathrm{H}), 7.23(\mathrm{~d}, J=8.7 \mathrm{~Hz}, 2 \mathrm{H}), 7.15(\mathrm{~d}, J=8.2 \mathrm{~Hz}, 1 \mathrm{H}), 7.01(\mathrm{~d}$, $J=8.1 \mathrm{~Hz}, 1 \mathrm{H}), 6.89$ (s, 1H), 5.17 (dd, $J=14.7,7.4 \mathrm{~Hz}, 1 \mathrm{H}), 3.42-3.35$ (m, 1H), 3.25-3.18 (m, 1H), 2.96-2.76 (m, 3H), $2.34(\mathrm{~d}, J=13.1 \mathrm{~Hz}, 1 \mathrm{H}), 2.04(\mathrm{~d}, J=11.1 \mathrm{~Hz}, 1 \mathrm{H}), 1.77-1.42(\mathrm{~m}, 7 \mathrm{H}), 1.31$ $\left(\mathrm{s}, 3 \mathrm{H}, \mathrm{CH}_{3}\right), 1.23\left(\mathrm{~d}, J=3.6 \mathrm{~Hz}, 6 \mathrm{H}, 2 \times \mathrm{CH}_{3}\right), 1.22\left(\mathrm{~s}, 3 \mathrm{H}, \mathrm{CH}_{3}\right) .{ }^{13} \mathrm{C} \mathrm{NMR}\left(100 \mathrm{MHz}, \mathrm{CDCl}_{3}\right)$ : $\delta 180.2,179.3,167.4,146.2,146.1,136.1,135.7,134.1,129.3,128.9,128.8,127.3,126.9,124.1$, 124.0, 123.9, 121.2, 61.4, 48.6, 45.3, 37.6, 37.3, 37.0, 36.9, 33.5, 29.7, 25.1, 23.9, 21.3, 18.5, 16.0. HR-MS $(m / z)(E S I)$ : calcd for $\mathrm{C}_{36} \mathrm{H}_{42} \mathrm{ClN}_{3} \mathrm{O}_{2} \mathrm{~S}\left[\mathrm{M}-\mathrm{H}^{+}\right]$: 614.26080; found: 614.26064.

(1R,4aS)-7-Isopropyl-N-(((R)-1-((2-methoxyphenyl)amino)-1-oxo-3-phenylpropan-2-yl)carbamothioyl)1,4a-dimethyl-1,2,3,4,4a,9,10,10a-octahydrophenanthrene-1-carboxamide (9f). Yields $80.28 \%,{ }^{1} \mathrm{H}$ NMR (400 MHz, $\left.\mathrm{CDCl}_{3}\right): \delta 11.39$ (d, $\left.J=7.3 \mathrm{~Hz}, 1 \mathrm{H}, \mathrm{NH}\right), 8.64(\mathrm{~s}, 1 \mathrm{H}, \mathrm{NH}), 8.41(\mathrm{~d}, J=9.3 \mathrm{~Hz}, 1 \mathrm{H}$, $\mathrm{NH}), 7.94(\mathrm{~s}, 1 \mathrm{H}), 7.37$ (d, $J=6.8 \mathrm{~Hz}, 3 \mathrm{H}), 7.33$ (s, 1H), 7.31 (d, $J=3.9 \mathrm{~Hz}, 1 \mathrm{H}), 7.20$ (d, J=8.2 Hz, $1 \mathrm{H}), 7.07-7.04(\mathrm{~m}, 2 \mathrm{H}), 6.97(\mathrm{~d}, J=7.7 \mathrm{~Hz}, 1 \mathrm{H}), 6.93(\mathrm{~s}, 1 \mathrm{H}), 6.82(\mathrm{~d}, J=8.1 \mathrm{~Hz}, 1 \mathrm{H}), 5.26(\mathrm{dd}$, $J=13.8,7.8 \mathrm{~Hz}, 1 \mathrm{H}), 3.72\left(\mathrm{~s}, 3 \mathrm{H}, \mathrm{OCH}_{3}\right), 3.52-3.47(\mathrm{~m}, 1 \mathrm{H}), 3.25-3.19(\mathrm{~m}, 1 \mathrm{H}), 2.95-2.84(\mathrm{~m}, 3 \mathrm{H})$, $2.38(\mathrm{~d}, J=13.0 \mathrm{~Hz}, 1 \mathrm{H}), 2.12(\mathrm{~d}, J=12.4 \mathrm{~Hz}, 1 \mathrm{H}), 1.78-1.49(\mathrm{~m}, 7 \mathrm{H}), 1.38\left(\mathrm{~s}, 3 \mathrm{H}, \mathrm{CH}_{3}\right), 1.28(\mathrm{~d}$, $\left.J=3.0 \mathrm{~Hz}, 6 \mathrm{H}, 2 \times \mathrm{CH}_{3}\right), 1.26\left(\mathrm{~s}, 3 \mathrm{H}, \mathrm{CH}_{3}\right) .{ }^{13} \mathrm{C} \mathrm{NMR}\left(100 \mathrm{MHz}, \mathrm{CDCl}_{3}\right): \delta 179.5,178.9,167.1$, $147.7,146.1,145.8,136.1,134.1,129.2,128.5,126.9,126.8,123.9,123.8,120.9,120.7,120.7,119.6$, $109.8,61.7,55.4,48.4,45.1,37.8,37.5,36.9,36.8,33.3,29.5,24.9,23.8,21.2,18.3,15.9$. HR-MS $(\mathrm{m} / z)(\mathrm{ESI})$ : calcd for $\mathrm{C}_{36} \mathrm{H}_{45} \mathrm{~N}_{3} \mathrm{O}_{3} \mathrm{~S}\left[\mathrm{M}-\mathrm{H}^{+}\right]$: 610.31033; found: 610.31051 .

(1R,4aS)-7-Isopropyl-N-(((R)-1-((4-methoxyphenyl)amino)-1-oxo-3-phenylpropan-2-yl)carbamothioyl)1,4a-dimethyl-1,2,3,4,4a,9,10,10a-octahydrophenanthrene-1-carboxamide (9g). Yields 81.57\%, ${ }^{1} \mathrm{H} \mathrm{NMR}$ (400 MHz, $\left.\mathrm{CDCl}_{3}\right): \delta 11.29(\mathrm{~d}, J=7.4 \mathrm{~Hz}, 1 \mathrm{H}, \mathrm{NH}), 8.55(\mathrm{~s}, 1 \mathrm{H}, \mathrm{NH}), 7.54(\mathrm{~s}, 1 \mathrm{H}), 7.33$ (d, $J=4.4 \mathrm{~Hz}, 4 \mathrm{H}), 7.26(\mathrm{~s}, 1 \mathrm{H}), 7.24(\mathrm{~s}, 1 \mathrm{H}), 7.16(\mathrm{~d}, J=8.2 \mathrm{~Hz}, 1 \mathrm{H}), 7.01(\mathrm{~d}, J=6.5 \mathrm{~Hz}, 1 \mathrm{H}), 6.89$ (s, $1 \mathrm{H}), 6.80(\mathrm{~d}, J=9.0 \mathrm{~Hz}, 2 \mathrm{H}), 5.14(\mathrm{dd}, J=14.4,7.8 \mathrm{~Hz}, 1 \mathrm{H}), 3.77\left(\mathrm{~s}, 3 \mathrm{H}, \mathrm{OCH}_{3}\right), 3.42-3.38(\mathrm{~m}, 1 \mathrm{H})$, $3.23-3.17(\mathrm{~m}, 1 \mathrm{H}), 2.89-2.79(\mathrm{~m}, 3 \mathrm{H}), 2.33(\mathrm{~d}, J=13.1 \mathrm{~Hz}, 1 \mathrm{H}), 2.05(\mathrm{~d}, J=12.4 \mathrm{~Hz}, 1 \mathrm{H}), 1.73-1.43$ $(\mathrm{m}, 7 \mathrm{H}), 1.32\left(\mathrm{~s}, 3 \mathrm{H}, \mathrm{CH}_{3}\right), 1.23\left(\mathrm{~d}, J=2.8 \mathrm{~Hz}, 6 \mathrm{H}, 2 \times \mathrm{CH}_{3}\right), 1.22\left(\mathrm{~s}, 3 \mathrm{H}, \mathrm{CH}_{3}\right) .{ }^{13} \mathrm{C} \mathrm{NMR}(100 \mathrm{MHz}$, $\left.\mathrm{CDCl}_{3}\right): \delta 179.8,179.2,167.1,156.5,146.2,146.0,136.3,134.2,130.1,129.4,128.8,127.2,126.9$, 124.0, 123.9, 121.8, 114.0, 61.5, 55.4, 48.6, 45.2, 37.6, 37.5, 37.0, 36.9, 33.4, 29.6, 25.1, 23.9, 21.3, 18.4, 16.04. HR-MS $(m / z)(E S I)$ : calcd for $\mathrm{C}_{36} \mathrm{H}_{45} \mathrm{~N}_{3} \mathrm{O}_{3} \mathrm{~S}\left[\mathrm{M}+\mathrm{Na}^{+}\right]$: 634.30793; found: 634.30579.

(1R,4aS)-N-(((R)-1-((2-Fluorophenyl)amino)-1-oxo-3-phenylpropan-2-yl)carbamothioyl)-7-isopropyl1,4a-dimethyl-1,2,3,4,4a,9,10,10a-octahydrophenanthrene-1-carboxamide (9h). Yields 85.27\%, ${ }^{1} \mathrm{H} \mathrm{NMR}$ $\left(400 \mathrm{MHz}, \mathrm{CDCl}_{3}\right): \delta 11.30(\mathrm{~d}, J=9.9 \mathrm{~Hz}, 1 \mathrm{H}, \mathrm{NH}), 8.60(\mathrm{~s}, 1 \mathrm{H}, \mathrm{NH}), 8.26(\mathrm{~s}, 1 \mathrm{H}, \mathrm{NH}), 7.91(\mathrm{dd}$, $J=13.0,2.3 \mathrm{~Hz}, 1 \mathrm{H}), 7.30(\mathrm{~s}, 3 \mathrm{H}), 7.28-7.21(\mathrm{~m}, 2 \mathrm{H}), 7.15(\mathrm{~d}, J=8.2 \mathrm{~Hz}, 1 \mathrm{H}), 7.11-7.05$ (m, 1H), $7.01(\mathrm{~d}, J=4.4 \mathrm{~Hz}, 2 \mathrm{H}), 6.99$ (d, $J=1.6 \mathrm{~Hz}, 1 \mathrm{H}), 6.88(\mathrm{~d}, J=5.4 \mathrm{~Hz}, 1 \mathrm{H}), 5.26(\mathrm{dd}, J=12.6$, 
$5.2 \mathrm{~Hz}, 1 \mathrm{H}), 3.42-3.35(\mathrm{~m}, 1 \mathrm{H}), 3.28-3.22(\mathrm{~m}, 1 \mathrm{H}), 2.92-2.79(\mathrm{~m}, 3 \mathrm{H}), 2.32(\mathrm{~d}, J=13.3 \mathrm{~Hz}, 1 \mathrm{H})$, 2.09-2.02 (m, 1H), 1.76-1.41 (m, 7H), $1.31\left(\mathrm{~s}, 3 \mathrm{H}, \mathrm{CH}_{3}\right), 1.23\left(\mathrm{~d}, J=2.5 \mathrm{~Hz}, 3 \mathrm{H}, \mathrm{CH}_{3}\right), 1.21(\mathrm{~d}$, $\left.J=2.2 \mathrm{~Hz}, 6 \mathrm{H}, 2 \times \mathrm{CH}_{3}\right) .{ }^{13} \mathrm{C} \mathrm{NMR}\left(100 \mathrm{MHz}, \mathrm{CDCl}_{3}\right): \delta 179.9,179.0,167.6,153.2,151.3,146.1$, $145.7,135.7,134.0,129.1,128.5,127.0,126.7,125.5,125.4,124.6,124.5,124.2,124.1,123.8,123.7$, 123.6, 121.8, 114.7, 114.5, 61.2, 48.3, 45.0, 37.4, 37.3, 36.8, 36.6, 33.2, 29.5, 24.9, 23.8, 21.1, 18.3, 15.8. HR-MS (m/z) (ESI): calcd for $\mathrm{C}_{36} \mathrm{H}_{42} \mathrm{FN}_{3} \mathrm{O}_{2} \mathrm{~S}\left[\mathrm{M}-\mathrm{H}^{+}\right.$]: 598.29035; found: 598.29175.

(1R,4aS)-N-(((R)-1-((4-Fluorophenyl)amino)-1-oxo-3-phenylpropan-2-yl)carbamothioyl)-7-isopropyl1,4a-dimethyl-1,2,3,4,4a,9,10,10a-octahydrophenanthrene-1-carboxamide (9i). Yields 80.13\%, ${ }^{1} \mathrm{H}$ NMR (400 MHz, $\left.\mathrm{CDCl}_{3}\right): \delta 11.35$ (d, $\left.J=7.3 \mathrm{~Hz}, 1 \mathrm{H}, \mathrm{NH}\right) .8 .63$ (s, 1H, NH), 8.03 (s, 1H, NH), $7.38(\mathrm{~d}, J=4.8 \mathrm{~Hz}, 1 \mathrm{H}), 7.37$ (s, 3H), $7.32(\mathrm{dd}, J=9.3,4.1 \mathrm{~Hz}, 2 \mathrm{H}), 7.21(\mathrm{~d}, J=8.2 \mathrm{~Hz}, 1 \mathrm{H}), 7.08$ (d, $J=9.7 \mathrm{~Hz}, 1 \mathrm{H}), 7.00(\mathrm{~d}, J=8.6 \mathrm{~Hz}, 2 \mathrm{H}), 6.96(\mathrm{~s}, 1 \mathrm{H}), 6.94(\mathrm{~s}, 1 \mathrm{H}), 5.25(\mathrm{dd}, J=14.5,7.4 \mathrm{~Hz}, 1 \mathrm{H})$, $3.55-3.38(\mathrm{~m}, 1 \mathrm{H}), 3.33-3.23(\mathrm{~m}, 1 \mathrm{H}), 2.95-2.87(\mathrm{~m}, 3 \mathrm{H}), 2.38(\mathrm{~d}, J=13.2 \mathrm{~Hz}, 1 \mathrm{H}), 2.08(\mathrm{~d}$, $J=12.5 \mathrm{~Hz}, 1 \mathrm{H}), 1.80-1.47(\mathrm{~m}, 7 \mathrm{H}), 1.35\left(\mathrm{~s}, 3 \mathrm{H}, \mathrm{CH}_{3}\right), 1.29\left(\mathrm{~d}, J=6.9 \mathrm{~Hz}, 6 \mathrm{H}, 2 \times \mathrm{CH}_{3}\right), 1.27(\mathrm{~s}, 3 \mathrm{H}$, $\left.\mathrm{CH}_{3}\right) .{ }^{13} \mathrm{C}$ NMR $\left(100 \mathrm{MHz}, \mathrm{CDCl}_{3}\right): \delta 179.7,179.0,167.5,160.2,158.3,146.0,145.7,135.9,133.9$, $132.9,129.1,128.5,127.0,126.7,123.9,123.8,121.8,115.4,115.2,61.2,48.4,45.1,37.4,36.8,36.8$, 36.6, 33.3, 29.5, 24.9, 23.7, 21.1, 18.3, 15.8. HR-MS (m/z) (ESI): calcd for $\mathrm{C}_{36} \mathrm{H}_{42} \mathrm{FN}_{3} \mathrm{O}_{2} \mathrm{~S}\left[\mathrm{M}-\mathrm{H}^{+}\right]$: 598.29035; found: 598.29118 .

(1R,4aS)-N-(((R)-1-((2-Bromophenyl)amino)-1-oxo-3-phenylpropan-2-yl)carbamothioyl)-7-isopropyl1,4a-dimethyl-1,2,3,4,4a,9,10,10a-octahydrophenanthrene-1-carboxamide $\quad(\mathbf{9 j}) . \quad$ Yields $88.33 \%$, ${ }^{1} \mathrm{H}$ NMR (400 MHz, $\left.\mathrm{CDCl}_{3}\right): \delta 11.21(\mathrm{~d}, J=7.4 \mathrm{~Hz}, 1 \mathrm{H}, \mathrm{NH}), 8.54(\mathrm{~s}, 1 \mathrm{H}, \mathrm{NH}), 8.28$ (d, $J=8.3 \mathrm{~Hz}$, 1H, NH), $7.91(\mathrm{~s}, 1 \mathrm{H}), 7.21(\mathrm{~d}, J=6.0 \mathrm{~Hz}, 4 \mathrm{H}), 7.19(\mathrm{~d}, J=1.4 \mathrm{~Hz}, 1 \mathrm{H}), 7.17-7.12(\mathrm{~m}, 2 \mathrm{H}), 7.07$ (d, $J=8.2 \mathrm{~Hz}, 1 \mathrm{H}), 6.95-6.90(\mathrm{~m}, 2 \mathrm{H}), 6.80(\mathrm{~d}, J=1.4 \mathrm{~Hz}, 1 \mathrm{H}), 5.21(\mathrm{dd}, J=14.2,7.5 \mathrm{~Hz}, 1 \mathrm{H})$, 3.35-3.28 (m, 1H), 3.20-3.13 (m, 1H), 2.83-2.71 (m, 3H), 2.24 (d, $J=13.1 \mathrm{~Hz}, 1 \mathrm{H}), 1.99(\mathrm{~d}, J=10.6 \mathrm{~Hz}$, $1 \mathrm{H}), 1.69-1.30(\mathrm{~m}, 7 \mathrm{H}), 1.24\left(\mathrm{~s}, 3 \mathrm{H}, \mathrm{CH}_{3}\right), 1.14\left(\mathrm{~d}, J=4.0 \mathrm{~Hz}, 6 \mathrm{H}, 2 \times \mathrm{CH}_{3}\right), 1.13\left(\mathrm{~s}, 3 \mathrm{H}, \mathrm{CH}_{3}\right)$. ${ }^{13} \mathrm{C} \mathrm{NMR}\left(100 \mathrm{MHz}, \mathrm{CDCl}_{3}\right): \delta 180.0,179.2,167.5,146.1,145.8,135.7,134.0,133.9,129.1,128.8$, $128.7,127.4,127.1,126.8,124.8,123.9,123.8,122.8,121.5,61.5,48.4,45.1,37.5,37.4,36.9,36.7$, $33.3,29.6,24.9,23.8,21.2,18.3,16.0$. HR-MS (m/z) (ESI): calcd for $\mathrm{C}_{36} \mathrm{H}_{42} \mathrm{BrN}_{3} \mathrm{O}_{2} \mathrm{~S}\left[\mathrm{M}+\mathrm{H}^{+}\right]$: 660.22594; found: 660.22639 .

(1R,4aS)-N-(((R)-1-((4-Bromophenyl)amino)-1-oxo-3-phenylpropan-2-yl)carbamothioyl)-7-isopropyl1,4a-dimethyl-1,2,3,4,4a,9,10,10a-octahydrophenanthrene-1-carboxamide $\quad(\mathbf{9 k}) . \quad$ Yields $82.34 \%$, ${ }^{1} \mathrm{H}$ NMR (400 MHz, $\left.\mathrm{CDCl}_{3}\right): \delta 11.32$ (d, $\left.J=7.4 \mathrm{~Hz}, 1 \mathrm{H}, \mathrm{NH}\right), 8.60$ (s, 1H, NH), 7.98 (s, 1H, NH), $7.40(\mathrm{~d}, J=8.8 \mathrm{~Hz}, 2 \mathrm{H}), 7.34(\mathrm{~d}, J=3.6 \mathrm{~Hz}, 4 \mathrm{H}), 7.33-7.31(\mathrm{~m}, 1 \mathrm{H}), 7.29(\mathrm{~d}, J=8.9 \mathrm{~Hz}, 2 \mathrm{H}), 7.19$ (d, $J=8.2 \mathrm{~Hz}, 1 \mathrm{H}), 7.05(\mathrm{~d}, J=8.2 \mathrm{~Hz}, 1 \mathrm{H}), 6.92(\mathrm{~s}, 1 \mathrm{H}), 5.22(\mathrm{dd}, J=14.6,7.4 \mathrm{~Hz}, 1 \mathrm{H}), 3.45-3.39$ (m, $1 \mathrm{H}), 3.28-3.21(\mathrm{~m}, 1 \mathrm{H}), 2.94-2.83(\mathrm{~m}, 3 \mathrm{H}), 2.37(\mathrm{~d}, J=13.1 \mathrm{~Hz}, 1 \mathrm{H}), 2.06(\mathrm{~d}, J=14.1 \mathrm{~Hz}, 1 \mathrm{H})$, 1.82-1.44 (m, 7H), $1.34\left(\mathrm{~s}, 3 \mathrm{H}, \mathrm{CH}_{3}\right), 1.27\left(\mathrm{~s}, 3 \mathrm{H}, \mathrm{CH}_{3}\right), 1.26\left(\mathrm{~s}, 6 \mathrm{H}, 2 \times \mathrm{CH}_{3}\right) .{ }^{13} \mathrm{C} \mathrm{NMR}(100 \mathrm{MHz}$, $\left.\mathrm{CDCl}_{3}\right): \delta 179.9,179.2,167.5,146.1,145.9,136.1,136.0,134.1,131.8,129.3,128.7,127.2,126.8$, 124.0, 123.9, 121.5, 117.1, 61.4, 48.5, 45.1, 37.5, 37.4, 36.9, 36.8, 33.4, 29.6, 25.0, 23.9, 21.2, 18.4, 15.9. HR-MS (m/z) (ESI): calcd for $\mathrm{C}_{36} \mathrm{H}_{42} \mathrm{BrN}_{3} \mathrm{O}_{2} \mathrm{~S}\left[\mathrm{M}+\mathrm{H}^{+}\right]$: 660.22594; found: 660.22566.

(1R,4aS)-N-(((R)-1-((3,5-Dimethylphenyl)amino)-1-oxo-3-phenylpropan-2-yl)carbamothioyl)-7-isopropyl1,4a-dimethyl-1,2,3,4,4a,9,10,10a-octahydrophenanthrene-1-carboxamide (91). Yields 82.57\%, 
${ }^{1} \mathrm{H}$ NMR (400 MHz, $\left.\mathrm{CDCl}_{3}\right): \delta 11.34(\mathrm{~d}, J=7.4 \mathrm{~Hz}, 1 \mathrm{H}, \mathrm{NH}), 8.62(\mathrm{~s}, 1 \mathrm{H}, \mathrm{NH}), 7.76(\mathrm{~s}, 1 \mathrm{H}), 7.37$ (d, $J=4.6 \mathrm{~Hz}, 4 \mathrm{H}), 7.20(\mathrm{~d}, J=8.2 \mathrm{~Hz}, 1 \mathrm{H}), 7.05(\mathrm{~s}, 3 \mathrm{H}), 6.94(\mathrm{~s}, 1 \mathrm{H}), 6.78(\mathrm{~s}, 1 \mathrm{H}), 5.23(\mathrm{dd}, J=14.4$, $7.5 \mathrm{~Hz}, 1 \mathrm{H}), 3.47-3.41(\mathrm{~m}, 1 \mathrm{H}), 3.31-3.25(\mathrm{~m}, 1 \mathrm{H}), 2.94-2.84(\mathrm{~m}, 3 \mathrm{H}), 2.30\left(\mathrm{~s}, 6 \mathrm{H}, 2 \times \mathrm{CH}_{3}\right)$, $1.82-1.51(\mathrm{~m}, 7 \mathrm{H}), 1.36\left(\mathrm{~s}, 3 \mathrm{H}, \mathrm{CH}_{3}\right), 1.29\left(\mathrm{~s}, 3 \mathrm{H}, \mathrm{CH}_{3}\right), 1.27\left(\mathrm{~s}, 6 \mathrm{H}, 2 \times \mathrm{CH}_{3}\right) .{ }^{13} \mathrm{C} \mathrm{NMR}(100 \mathrm{MHz}$, $\left.\mathrm{CDCl}_{3}\right): \delta 179.9,179.2,167.2,146.2,146.0,138.6,136.9,136.3,134.2,129.3,128.8,127.1,126.9$, 126.3, 124.0, 123.9, 117.7, 61.5, 48.5, 45.2, 37.6, 37.4, 37.0, 36.9, 33.4, 29.6, 25.0, 23.9, 21.3, 21.2, 18.4, 16.0. HR-MS (m/z) (ESI): calcd for $\mathrm{C}_{38} \mathrm{H}_{47} \mathrm{~N}_{3} \mathrm{O}_{2} \mathrm{~S}\left[\mathrm{M}-\mathrm{H}^{+}\right]$: 608.33107; found: 608.33232 .

(1R,4aS)-7-Isopropyl-1,4a-dimethyl-N-(((R)-1-(naphthalen-1-ylamino)-1-oxo-3-phenylpropan-2-yl) carbamothioyl)-1,2,3,4,4a,9,10,10a-octahydrophenanthrene-1-carboxamide (9m). Yields 84.09\%, ${ }^{1} \mathrm{H}$ NMR (400 MHz, $\left.\mathrm{CDCl}_{3}\right): \delta 11.34(\mathrm{~d}, J=7.5 \mathrm{~Hz}, 1 \mathrm{H}, \mathrm{NH}), 8.62(\mathrm{~s}, 1 \mathrm{H}, \mathrm{NH}), 8.18(\mathrm{~s}, 1 \mathrm{H}, \mathrm{NH})$, $7.94(\mathrm{~d}, J=7.5 \mathrm{~Hz}, 1 \mathrm{H}), 7.79(\mathrm{~d}, J=8.0 \mathrm{~Hz}, 1 \mathrm{H}), 7.64(\mathrm{~d}, J=8.2 \mathrm{~Hz}, 1 \mathrm{H}), 7.42(\mathrm{~d}, J=8.0 \mathrm{~Hz}, 2 \mathrm{H})$, $7.38(\mathrm{~d}, J=5.8 \mathrm{~Hz}, 4 \mathrm{H}), 7.35-7.30(\mathrm{~m}, 3 \mathrm{H}), 7.15(\mathrm{~d}, J=8.2 \mathrm{~Hz}, 1 \mathrm{H}), 7.01(\mathrm{~d}, J=8.0 \mathrm{~Hz}, 1 \mathrm{H}), 6.88$ (s, 1H), $5.42(\mathrm{dd}, J=14.6,7.4 \mathrm{~Hz}, 1 \mathrm{H}), 3.43(\mathrm{~d}, J=6.4 \mathrm{~Hz}, 1 \mathrm{H}), 3.35-3.28(\mathrm{~m}, 1 \mathrm{H}), 2.89-2.78$ (m, 3H), $2.32(\mathrm{~d}, J=13.2 \mathrm{~Hz}, 1 \mathrm{H}), 2.07(\mathrm{~s}, 1 \mathrm{H}), 1.75-1.43(\mathrm{~m}, 7 \mathrm{H}), 1.30\left(\mathrm{~s}, 3 \mathrm{H}, \mathrm{CH}_{3}\right), 1.23(\mathrm{~s}, 3 \mathrm{H}$, $\left.\mathrm{CH}_{3}\right), 1.21\left(\mathrm{~s}, 6 \mathrm{H}, 2 \times \mathrm{CH}_{3}\right) .{ }^{13} \mathrm{C} \mathrm{NMR}\left(100 \mathrm{MHz}, \mathrm{CDCl}_{3}\right): \delta 180.2,179.3,168.0,146.2,146.1,136.3$, $134.2,133.9,131.8,129.4,129.0,128.5,127.2,126.9,126.5,126.2,125.9,125.7,125.6,124.1,123.9$, $120.9,120.1,61.6,48.6,45.2,37.6,37.5,37.0,36.9,33.4,29.7,25.1,23.9,21.3,18.5,16.1$. HR-MS $(\mathrm{m} / z)(\mathrm{ESI})$ : calcd for $\mathrm{C}_{40} \mathrm{H}_{45} \mathrm{~N}_{4} \mathrm{O}_{2} \mathrm{~S}\left[\mathrm{M}-\mathrm{H}^{+}\right]$: 630.31542; found: 630.31666 .

(1R,4aS)-7-Isopropyl-1,4a-dimethyl-N-(((R)-1-oxo-3-phenyl-1-(pyridin-2-ylamino)propan-2-yl)carb amothioyl)-1,2,3,4,4a,9,10,10a-octahydrophenanthrene-1-carboxamide (9n). Yields 88.56\%, ${ }^{1} \mathrm{H} \mathrm{NMR}$ (400 MHz, $\left.\mathrm{CDCl}_{3}\right): \delta 11.19$ (d, $\left.J=7.1 \mathrm{~Hz}, 1 \mathrm{H}, \mathrm{NH}\right), 9.09$ (s, 1H, NH), 8.57 (s, 1H), 8.23 (d, $J=6.3 \mathrm{~Hz}$, 2H), $7.71(\mathrm{~s}, 1 \mathrm{H}), 7.25(\mathrm{~d}, J=3.7 \mathrm{~Hz}, 4 \mathrm{H}), 7.15(\mathrm{~d}, J=8.2 \mathrm{~Hz}, 1 \mathrm{H}), 7.06(\mathrm{~d}, J=5.9 \mathrm{~Hz}, 1 \mathrm{H}), 7.01(\mathrm{~d}$, $J=8.2 \mathrm{~Hz}, 1 \mathrm{H}), 6.89(\mathrm{~s}, 1 \mathrm{H}), 5.23(\mathrm{dd}, J=14.3,7.8 \mathrm{~Hz}, 1 \mathrm{H}), 3.35-3.26(\mathrm{~m}, 2 \mathrm{H}), 2.90-2.80(\mathrm{~m}, 3 \mathrm{H})$, $2.33(\mathrm{~d}, J=13.3 \mathrm{~Hz}, 1 \mathrm{H}), 2.05(\mathrm{~d}, J=12.5 \mathrm{~Hz}, 1 \mathrm{H}), 1.76-1.49(\mathrm{~m}, 7 \mathrm{H}), 1.31\left(\mathrm{~s}, 3 \mathrm{H}, \mathrm{CH}_{3}\right), 1.23(\mathrm{~d}$, $\left.J=3.5 \mathrm{~Hz}, 6 \mathrm{H}, 2 \times \mathrm{CH}_{3}\right), 1.22\left(\mathrm{~s}, 3 \mathrm{H}, \mathrm{CH}_{3}\right) .{ }^{13} \mathrm{C} \mathrm{NMR}\left(100 \mathrm{MHz}, \mathrm{CDCl}_{3}\right): \delta 180.4,178.9,168.3$, $150.8,147.5,146.2,146.0,138.5,135.7,134.2,129.3,128.6,127.2,126.9,124.0,123.9,120.0,114.5$, 61.6, 48.5, 45.1, 37.7, 37.6, 37.0, 36.9, 33.4, 29.6, 25.0, 23.9, 21.3, 18.4, 16.0. HR-MS (m/z) (ESI): calcd for $\mathrm{C}_{37} \mathrm{H}_{42} \mathrm{~N}_{4} \mathrm{O}_{2} \mathrm{~S}\left[\mathrm{M}+\mathrm{H}^{+}\right]$: 583.31067; found: 583.3098 .

(1R,4aS)-7-Isopropyl-1,4a-dimethyl-N-(((R)-1-oxo-3-phenyl-1-((3,4,5-trimethoxyphenyl)amino)propan2-yl)carbamothioyl)-1,2,3,4,4a,9,10,10a-octahydrophenanthrene-1-carboxamide (9o). Yields 85.32\%, ${ }^{1} \mathrm{H}$ NMR (400 MHz, $\mathrm{CDCl}_{3}$ ): $\delta 11.32$ (d, $\left.J=7.3 \mathrm{~Hz}, 1 \mathrm{H}, \mathrm{NH}\right), 8.59$ (s, 1H, NH), 7.80 (s, 1H), 7.34 $(\mathrm{d}, J=4.4 \mathrm{~Hz}, 4 \mathrm{H}), 7.17(\mathrm{~d}, J=8.2 \mathrm{~Hz}, 1 \mathrm{H}), 7.03(\mathrm{~d}, J=8.2 \mathrm{~Hz}, 1 \mathrm{H}), 6.90(\mathrm{~s}, 1 \mathrm{H}), 6.67(\mathrm{~s}, 2 \mathrm{H}), 5.19$ $(\mathrm{dd}, J=14.5,7.4 \mathrm{~Hz}, 1 \mathrm{H}), 3.81\left(\mathrm{~s}, 12 \mathrm{H}, 3 \times \mathrm{OCH}_{3}\right), 3.45-3.40(\mathrm{~m}, 1 \mathrm{H}), 3.27-3.21(\mathrm{~m}, 1 \mathrm{H}), 2.92-2.81$ $(\mathrm{m}, 3 \mathrm{H}), 2.35(\mathrm{~d}, J=13.2 \mathrm{~Hz}, 1 \mathrm{H}), 2.06(\mathrm{~d}, J=10.8 \mathrm{~Hz}, 1 \mathrm{H}), 1.78-1.48(\mathrm{~m}, 7 \mathrm{H}), 1.33\left(\mathrm{~s}, 3 \mathrm{H}, \mathrm{CH}_{3}\right)$, $1.24\left(\mathrm{~d}, J=4.6 \mathrm{~Hz}, 6 \mathrm{H}, 2 \times \mathrm{CH}_{3}\right), 1.23\left(\mathrm{~s}, 3 \mathrm{H}, \mathrm{CH}_{3}\right) .{ }^{13} \mathrm{C} \mathrm{NMR}\left(100 \mathrm{MHz}, \mathrm{CDCl}_{3}\right): \delta 179.8,179.2$, $167.3,153.0,146.0,145.9,136.1,134.6,134.0,133.1,129.3,128.7,127.0,126.8,124.0,123.8,97.4$, $61.4,60.8,55.9,48.5,45.1,37.5,37.4,36.9,36.8,33.3,29.5,24.9,23.8,21.2,18.3,15.9$. HR-MS $(\mathrm{m} / \mathrm{z})$ (ESI): calcd for $\mathrm{C}_{39} \mathrm{H}_{49} \mathrm{~N}_{3} \mathrm{O}_{5} \mathrm{~S}\left[\mathrm{M}-\mathrm{H}^{+}\right]$: 670.33146; found: 670.33304 . 


\subsection{Biological Assays}

\subsubsection{Cytotoxicity of Rhein Derivatives}

General procedure for cytotoxic evaluation in vitro: HeLa, HepG2, SK-OV-3 and MGC-803 cells were seeded into 96-well microculture plates and allowed to adhere for $24 \mathrm{~h}$, respectively. After cells were exposed to compounds at concentrations from 100 to $0.01 \mu \mathrm{M}$ for $48 \mathrm{~h}$, medium was aspirated and replenished with complete medium. IC 50 was evaluated by MTT tetrazolium dye assay. Each experiment was performed three times; Statistical analysis: All statistical analysis was performed with SPSS Version 10 (SPSS, Chicago, IL, USA). Data was analyzed by one-way ANOVA. Mean separations were performed using the least significant difference method. Each experiment was replicated thrice, and all experiments yielded similar results. Measurements from all the replicates were combined, and treatment effects were analyzed.

\subsubsection{Apoptosis Assessment by AO/EB Staining}

Cells were seeded at a concentration of $5 \times 104$ cell $/ \mathrm{mL}$ in a volume of $2 \mathrm{~mL}$ on a sterile cover slip in six-well tissue culture plates. Following incubation, the medium was removed and replaced with fresh medium plus $10 \%$ fetal bovine serum and supplemented with compound 9n $(15 \mu \mathrm{M})$. After the treatment period, the cover slip with monolayer cells was inverted on a glass slide with $20 \mu \mathrm{L}$ of $\mathrm{AO} / \mathrm{EB}$ stain $(100 \mathrm{mg} / \mathrm{mL})$. Fluorescence was read on a slide with $20 \mu \mathrm{L}$ of $\mathrm{AO} / \mathrm{EB}$ stain (100 mg/mL) using a Nikon ECLIPSETE2000-S fluorescence microscope (Olympus, Tokyo, Japan).

\subsubsection{Hoechst 33258 Staining}

General procedure for Hoechst 33258 staining: cells grown on a sterile cover slip in six-well tissue culture plates were treated with compounds for a certain range of time. The culture medium containing compounds was removed, and the cells were fixed in 4\% paraformaldehyde for $10 \mathrm{~min}$. After being washed twice with PBS, the cells were stained with $0.5 \mathrm{~mL}$ of Hoechst 33258 (Beyotime, Jiangsu, China) for $5 \mathrm{~min}$ and then again washed twice with PBS. The stained nuclei were observed under a Nikon ECLIPSETE2000-S fluorescence microscope using $350 \mathrm{~nm}$ excitation and $460 \mathrm{~nm}$ emission.

\subsubsection{JC-1 Staining}

General procedure for mitochondrial membrane potential staining: JC-1 probe was employed to measure mitochondrial depolarization in NCI-H460 cells. Briefly, cells cultured in six-well plates after indicated treatments were incubated with an equal volume of JC-1 staining solution $(5 \mu \mathrm{g} / \mathrm{mL})$ at $37{ }^{\circ} \mathrm{C}$ for $20 \mathrm{~min}$ and rinsed twice with PBS. Mitochondrial membrane potentials were monitored by determining the relative amounts of dual emissions from mitochondrial JC-1 monomers or aggregates using an Nikon ECLIPSETE2000-S fluorescent microscope. Mitochondrial depolarization is indicated by an increase in the green/red fluorescence intensity ratio. 


\subsubsection{TUNEL Assay}

The TUNEL method was performed to label the 3'-end of fragmented DNA of the apoptotic HeLa cells. The cells treated as indicated were fixed with $4 \%$ paraformaldehyde phosphate buffer saline, rinsed with PBS, then permeabilized by $0.1 \%$ Triton X-100 for FITC end-labeling the fragmented DNA of the apoptotic HeLa cells using TUNEL cell (Beyotime, Jiangsu, China) apoptosis detection kit. The FITC-labeled TUNEL-positive cells were imaged under a fluorescent microscopy by using $488 \mathrm{~nm}$ excitation and $530 \mathrm{~nm}$ emission.

\subsubsection{Apoptosis Study by Flow Cytometry Assay}

General procedure apoptosis ratios: Prepared HeLa cells $(1 \times 106$ cells $/ \mathrm{mL})$ were washed twice with cold PBS and then re-suspended gently in $500 \mu \mathrm{L}$ of binding buffer. Thereafter, cells were stained in $5 \mu \mathrm{L}$ of Annexin V-FITC and shaken well. Finally, the cells were mixed with $5 \mu \mathrm{L}$ of PI, incubated for $20 \mathrm{~min}$ in the dark and subsequently analyzed using FACSCalibur (Becton Dickinson, Franklin Lakes, NJ, USA).

\subsubsection{Investigation of Cell Cycle Distribution}

General procedure cell cycle: HeLa cells were maintained in Dulbecco's modified Eagle's medium with $10 \%$ fetal calf serum in $5 \% \mathrm{CO}_{2}$ at $37^{\circ} \mathrm{C}$. Cells were harvested by trypsinization and rinsed with PBS. After centrifugation, the pellet $\left(10^{5}-10^{6}\right.$ cells) was suspended in $1 \mathrm{~mL}$ of PBS and kept on ice for $5 \mathrm{~min}$. The cell suspension was then fixed by the drop-wise addition of $9 \mathrm{~mL}$ precooled $\left(4{ }^{\circ} \mathrm{C}\right) 75 \%$ ethanol with violent shaking. Fixed samples were kept at $4{ }^{\circ} \mathrm{C}$ until use. For staining, cells were centrifuged, resuspended in PBS, digested with $500 \mu \mathrm{L}$ of RNase A $(250 \mathrm{mg} / \mathrm{mL})$, and treated with $25 \mu \mathrm{L}$ of propidium iodide (PI) $(0.15 \mathrm{mM})$, then incubated for $30 \mathrm{~min}$ at $4{ }^{\circ} \mathrm{C}$. PI-positive cells were counted with a FACScan Fluorescence-activated cell sorter (FACS). The population of cells in each cell-cycle phase was determined using Cell Modi FIT software (Becton Dickinson).

\subsection{Statistics}

The data were processed by the Student's $t$-test with the significance level $p \leq 0.05$ using SPSS.

\section{Conclusions}

In this study, a series of novel DHAA acyl-thiourea derivatives were designed and synthesized, and their cell growth inhibition activities against the HeLa, SK-OV-3 and MGC-803 cell lines and the HL-7702 normal human river cell line were evaluated using MTT assay. The in vitro antitumor activity screening revealed that some compounds exhibited better inhibition activities than the commercial anticancer drug 5-FU. The apoptosis-inducing activity of representative compound 9n in HeLa cells were investigated by acridine orange/ethidium bromide staining, Hoechst 33258 staining, JC-1 mitochondrial membrane potential staining, TUNEL assay and flow cytometry. Cell cycle analysis indicated that compound 9n could arrest the HeLa cell line in S stage. Furthermore, molecular mechanism studies suggested that compound 9n was found to induce apoptosis in HeLa cells via the 
mitochondrial pathway, including an increase of the production of ROS and intracellular $\mathrm{Ca}^{2+}$, loss of mitochondrial membrane potential and activation of caspase-3. The above results demonstrate that the rational design of DHAA acyl derivatives as novel antitumor leads is feasible. Investigations into the precise mechanisms of action is currently under way.

\section{Acknowledgments}

This study was supported by the National Natural Science Foundation of China (No. 81260472 and 21362002), Guangxi Natural Science Foundation of China (No. 2014GXNSFDA118007 and 2014GXNSFBA118050), "BAGUI Scholar" Project, the State Key Laboratory Cultivation Base for the Chemistry and Molecular Engineering of Medicinal Resources, Ministry of Science and Technology of China (CMEMR2014-B14), the Innovation Program for Graduate Students in Jiangsu Province and the Foundation of Ministry of Education Innovation Team (NO. IRT1225).

\section{Author Contributions}

Heng-Shan Wang and Le Jin conceived and designed the studies; Xiao-Chao Huang performed the database search; Le Jin and Hong-En Qu performed the experiments, Ye Zhang, Ying-Ming Pan, Dong Liang and Zhen-Feng Chen provided overall supervision and guidance; all the authors analyzed data, discussed the results and contributed to write the paper.

\section{Conflict of Interest}

The authors declare no conflict of interest.

\section{References}

1. Son, K.H.; Oh, H.M.; Choi, S.K.; Han, D.C.; Kwon, B.M. Anti-tumor abietane diterpenes from the cones of Sequoia sempervirens. Bioorg. Med. Chem. Lett. 2005, 15, 2019-2021.

2. Newman, D.J.; Cragg, G.M.; Snade, K.M. Natural products as sources of new drugs over the period 1981-2002. J. Nat. Prod. 2003, 66, 1022-1037.

3. Kubisch, R.V.; Gamm, M.; Braig, S.; Ullrich, A.; Burkhart, J.L.; Colling, L.; Vollmar, A.M. Simplified Pretubulysin Derivatives and Their Biological Effects on Cancer Cells. J. Nat. Prod. 2014, 77, 536-542.

4. Newman, D.J.; Cragg, G.M. Natural products as sources of new drugs over the 30 years from 1981 to 2010. J. Nat. Prod. 2012, 75, 311-335.

5. Gigante, B.; Silva, A.M.; Marcelo-Curto, M.J.; Feio, S.S.; Roseiro, J.; Reis, L.V. Structural effects on the bioactivity of dehydroabietic acid derivatives. Planta Med. 2002, 68, 680-684.

6. Wasowski, C.; Marder, M. Central nervous system activities of two diterpenes isolated from Aloysia virgata. Phytomedicine 2011, 18, 393-401.

7. Lee, C.L.; Chiang, L.C.; Cheng, L.H.; Liaw, C.C.; Abd El-Razek, M.H.; Chang, F.R.; Wu, Y.C. Influenza A (H1N1) antiviral and cytotoxic agents from Ferula assa-foetida. J. Nat. Prod. 2009, 72, $1568-1572$. 
8. Zapata, B.; Rojas, M.; Betancur-Galvis, L.; Mesa-Arango, A.C.; Pérez-Guaita, D.; González, M.A. Cytotoxic, immunomodulatory, antimycotic, and antiviral activities of semisynthetic 14-hydroxyabietane derivatives and triptoquinone C-4 epimers. MedChem Comm 2013, 4, 1239-1246.

9. González, M.A.; Pérez-Guaita, D.; Correa-Royero, J.; Zapata, B.; Agudelo, L.; Mesa-Arango, A.; Betancur-Galvis, L. Synthesis and biological evaluation of dehydroabietic acid derivatives. Eur. J. Med. Chem. 2010, 45, 811-816.

10. Huang, X.C.; Wang, M.; Pan, Y.M.; Yao, G.Y.; Wang, H.S.; Tian, X.Y.; Zhang, Y. Synthesis and antitumor activities of novel thiourea $\alpha$-aminophosphonates from dehydroabietic acid. Eur. J. Med. Chem. 2013, 69, 508-520.

11. Huang, X.C.; Wang, M.; Wang, H.S.; Chen, Z.F.; Zhang, Y.; Pan, Y.M. Synthesis and antitumor activities of novel dipeptide derivatives derived from dehydroabietic acid. Bioorg. Med. Chem. Lett. 2014, 24, 1511-1518.

12. Huang, X.C.; Wang, M.; Pan, Y.M.; Tian, X.Y.; Wang, H.S.; Zhang, Y. Synthesis and antitumor activities of novel $\alpha$-aminophosphonates dehydroabietic acid derivatives. Bioorg. Med. Chem. Lett. 2013, 23, 5283-5289.

13. Cui, Y.M.; Yasutomi, E.; Otani, Y.; Yoshinaga, T.; Ido, K.; Sawada, K.; Ohwada, T. Novel BK channel openers containing dehydroabietic acid skeleton: Structure-activity relationship for peripheral substituents on ring C. Bioorg. Med. Chem. Lett. 2008, 18, 5201-5205.

14. Rao, X.; Song, Z.; He, L.; Jia, W. Synthesis, structure analysis and cytotoxicity studies of novel unsymmetrically N, N'-substituted ureas from dehydroabietic Acid. Chem. Pharm. Bull. 2008, 56, 1575-1578.

15. Tanaka, R.; Tokuda, H.; Ezaki, Y. Cancer chemopreventive activity of "rosin" constituents of Pinus spez and their derivatives in two-stage mouse skin carcinogenesis test. Phytomedicine 2008, 15, 985-992.

16. Li, F.; He, L.; Song, Z.Q.; Yao, J.C.; Rao, X.P.; Li, H.T. Cytotoxic effects and pro-apoptotic mechanism of TBIDOM, a novel dehydroabietylamine derivative, on human hepatocellular carcinoma SMMC-7721 cells. J. Pharm. Pharmacol. 2008, 60, 205-211.

17. Koca, İ.; Özgür, A.; Coşkun, K.A.; Tutar, Y. Synthesis and anticancer activity of acyl thioureas bearing pyrazole moiety. Bioorg. Med. Chem. 2013, 21, 3859-3865.

18. Bunz, F. Cell death and cancer therapy. Curr. Opin. Pharmacol. 2001, 1, 337-341.

19. Wang, C.; Youle, R.J. The role of mitochondria in apoptosis. Annu. Rev. Genet. 2009, 43, 95-118.

20. Tan, C.; Lai, S.; Wu, S.; Hu, S.; Zhou, L.; Chen, Y.; Xu, A. Nuclear permeable ruthenium (II) $\beta$-carboline complexes induce autophagy to antagonize mitochondrial-mediated apoptosis. J. Med. Chem. 2010, 53, 7613-7624.

21. Nowak, G. Protein kinase C-alpha and ERK1/2 mediate mitochondrial dysfunction, decreases in active $\mathrm{Na}^{+}$transport, and cisplatin-induced apoptosis in renal cells. J. Biol. Chem. 2002, 277, 43377-43388.

22. Zhang, J.Y.; Wu, H.Y.; Xia, X.K.; Liang, Y.J.; Yan, Y.Y.; She, Z.G.; Fu, L.W. Anthracenedione derivative 1403P-3 induces apoptosis in $\mathrm{KB}$ and $\mathrm{KBv} 200$ cells via reactive oxygen species-independent mitochondrial pathway and death receptor pathway. Cancer Biol. Ther. 2007, 6, 1409-1417. 
23. Quan, Z.; Gu, J.; Dong, P.; Lu, J.; Wu, X.; Wu, W.; Liu, Y. Reactive oxygen species-mediated endoplasmic reticulum stress and mitochondrial dysfunction contribute to cirsimaritin-induced apoptosis in human gallbladder carcinoma GBC-SD cells. Cancer Lett. 2010, 295, 252-259.

24. Wang, X.H.; Jia, D.Z.; Liang, Y.J.; Yan, S.L.; Ding, Y.; Chen, L.M.; Fu, L.W. Lgf-YL-9 induces apoptosis in human epidermoid carcinoma KB cells and multidrug resistant KBv200 cells via reactive oxygen species-independent mitochondrial pathway. Cancer Lett. 2007, 249, 256-270.

25. Zamzami, N.; Marchetti, P.; Castedo, M.; Decaudin, D.; Macho, A.; Hirsch, T.; Kroemer, G. Sequential reduction of mitochondrial transmembrane potential and generation of reactive oxygen species in early programmed cell death. J. Exp. Med. 1995, 182, 367-377.

26. Ashkenazi, A.; Dixit, V.M. Apoptosis control by death and decoy receptors. Curr. Opin. Cell Biol. 1999, 11, 255-260.

27. Kamachi, M.; Le, T.M.; Kim, S.J.; Geiger, M.E.; Anderson, P.; Utz, P.J. Human autoimmune sera as molecular probes for the identification of an autoantigen kinase signaling pathway. J. Exp. Med. 2002, 196, 1213-1226.

28. Liu, D.; Tian, Z.; Yan, Z.; Wu, L.; Ma, Y.; Wang, Q.; Yang, C. Design, synthesis and evaluation of 1,2-benzisothiazol-3-one derivatives as potent caspase-3 inhibitors. Bioorg. Med. Chem. 2013, 21, 2960-2967.

29. Vickers, C.J.; González-Páez, G.E.; Wolan, D.W. Selective detection and inhibition of active caspase-3 in cells with optimized peptides. J. Am. Chem. Soc. 2013, 135, 12869-12876.

30. Huang, K.B.; Chen, Z.F.; Liu, Y.C.; Li, Z.Q.; Wei, J.H.; Wang, M.; Liang, H. Platinum (II) complexes containing aminophosphonate esters: Synthesis, characterization, cytotoxicity and action mechanism. Eur. J. Med. Chem. 2013, 64, 554-561.

(C) 2015 by the authors; licensee MDPI, Basel, Switzerland. This article is an open access article distributed under the terms and conditions of the Creative Commons Attribution license (http://creativecommons.org/licenses/by/4.0/). 